\title{
Idioblasts and peltate hairs as distribution networks for water absorbed by the leaves of Capparis odoratissima
}

\author{
Juan Losada ${ }^{1}$, Miriam Diaz ${ }^{2}$, and Noel Holbrook ${ }^{3}$ \\ ${ }^{1} \mathrm{CSIC}$ \\ ${ }^{2}$ Universidad Francisco de Miranda \\ ${ }^{3}$ Harvard University
}

September 22, 2020

\begin{abstract}
Capparis odoratissima is a tree species native to semi-arid environments of the northern coast of South America where low soil water availability coexists with frequent nighttime fog. A previous study showed that water applied to leaf surfaces enhanced leaf hydration, photosynthesis, and growth, but the mechanisms of foliar water uptake are unknown. Here we combine detailed anatomical evaluations with water and dye uptake experiments in the laboratory, and use immunolocalization of pectin and arabinogalactan protein epitopes to characterize water uptake pathways in leaves. Abaxially, the leaves of C. odoratissima are covered with peltate hairs, while the adaxial surfaces are glabrous. Both surfaces are able to absorb condensed water, but the lower surface has higher rates of water uptake. Numerous idioblasts connect the adaxial leaf surface and the abaxial peltate hairs, both of which contain hygroscopic substances such as arabinogalactan proteins and pectins. The highly specialized anatomy of the leaves of $\mathrm{C}$ odoratissima fulfills the dual function of minimizing water loss when stomata are closed, while maintaining the ability to absorb liquid water. Cell-wall related hygroscopic compounds in the peltate hairs and idioblasts create a network of microchannels that maintain leaf hydration and promote water uptake.
\end{abstract}

\section{Article title:}

Idioblasts and peltate hairs as distribution networks for water absorbed by the leaves of Capparis odoratissima

\section{Short running:}

Idioblasts and foliar water uptake

\section{Authors:}

Juan M. Losada ${ }^{1,3,4^{*}}$

Miriam Díaz ${ }^{2}$

N. Michele Holbrook ${ }^{3,4}$

${ }^{1}$ Instituto de Hortofruticultura Subtropical y Mediterránea La Mayora. Avda. Dr. Wienberg s/n, AlgarroboCosta, 29750, Málaga, Spain.

${ }^{2}$ Centro de Investigaciones en Ecología y Zonas Áridas (CIEZA), Universidad Nacional Experimental Francisco de Miranda, Venezuela.

${ }^{3}$ Department of Organismic and Evolutionary Biology. 16 Divinity Avenue Cambridge, MA 02138, USA.

${ }^{4}$ Arnold Arboretum of Harvard University. 1300 Centre St. Boston, MA 02131. 
*Author for correspondence:

Phone: + 34 (689) 258686

E-mail: juan.losada@csic.es

\section{SUMMARY}

Capparis odoratissima is a tree species native to semi-arid environments of the northern coast of South America where low soil water availability coexists with frequent nighttime fog. A previous study showed that water applied to leaf surfaces enhanced leaf hydration, photosynthesis, and growth, but the mechanisms of foliar water uptake are unknown. Here we combine detailed anatomical evaluations with water and dye uptake experiments in the laboratory, and use immunolocalization of pectin and arabinogalactan protein epitopes to characterize water uptake pathways in leaves. Abaxially, the leaves of $C$. odoratissima are covered with peltate hairs, while the adaxial surfaces are glabrous. Both surfaces are able to absorb condensed water, but the lower surface has higher rates of water uptake. Numerous idioblasts connect the adaxial leaf surface and the abaxial peltate hairs, both of which contain hygroscopic substances such as arabinogalactan proteins and pectins. The highly specialized anatomy of the leaves of $C$ odoratissima fulfills the dual function of minimizing water loss when stomata are closed, while maintaining the ability to absorb liquid water. Cell-wall related hygroscopic compounds in the peltate hairs and idioblasts create a network of microchannels that maintain leaf hydration and promote water uptake.

Keywork index : arabinogalactan proteins-AGPs, foliar water uptake, idioblast, pectins, peltate hairs, sclerenchyma.

\section{INTRODUCTION}

Water-energy dynamics drive global patterns of plant diversity (Kreft \& Jetz, 2007), with the predicted global increase of aridity likely to make plants more vulnerable to a lack of water in the soil (Choat et al., 2018; Olson et al., 2018). In arid and semiarid environments, plant productivity is compromised due to prolonged soil drought. Xerophilous plants that thrive in these ecosystems exhibit anatomical adaptations that reduce rates of water loss, such as smaller leaves, lower stomata index and impermeable coating structures, like cuticles (see Shields, 1950). Surprisingly, some of the structures that prevent evaporative water loss may also facilitate aerial water uptake, decoupling the water status of the canopy from soil water availability (Benzing et al., 1978; Gouvra \& Grammatikopoulos, 2003).

Foliar water uptake is a widespread phenomenon of vascular plants, known for three centuries, and evaluated in at least 53 plant families (Dawson \& Goldsmith, 2018). Foliar water uptake has direct consequences on plant function, relaxing tension in the water column of the xylem, enhancing turgor-driven growth, and increasing the productivity of agricultural and natural ecosystems (Mayr et al., 2014; Steppe et al., 2018; Aguirre-Gutiérrrez et al., 2019). The key conditions for foliar water uptake are met in fog-dominated environments (Tognetti, 2015; Weathers et al., 2019), where high atmospheric humidity enhances nighttime dew formation on leaf surfaces, thus increasing the possibility of foliar water absorption. Indeed, studies in montane cloud forests of Brazil (Eller et al., 2016), coastal California redwood forests in the USA (Burgess \& Dawson, 2004), and cloud forests in Mexico (Gotsch et al., 2014) have demonstrated that aerial water has an important impact on plant functioning, especially during dry periods. Foliar uptake in semiarid areas of the tropics is less studied, despite reports that it can enhance biomass productivity (Díaz \& Granadillo, 2005; Limm et al., 2009). Better characterization of the pathways of foliar absorption will enhance understanding of the mechanisms semiarid plants use to hydrate their leaves with aerial water.

Foliar water uptake occurs through a variety of mechanisms and pathways. Some species absorb water through the natural leaf openings, such as stomata (Burkhardt et al., 2012; Berry et al., 2014) or hydathodes (Martin \& von Willert, 2000; Boanares et al., 2019). Other structures that are supposedly impermeable to water may participate in aerial water uptake, including cuticles (Vaadia \& Waisel, 1963; Yates \& Hutley, 1995; 
Fernández et al., 2017; Schuster et al., 2017), and trichomes (Franke, 1967; Benzing et al., 1978; reviewed by Berry et al., 2019). While the use of these wall-thickened, sealing structures appears as a good strategy to capture atmospheric water condensed on leaf surfaces, demonstration of their hygroscopic capacity requires a careful examination of their cell wall biochemistry, so far lacking for most plant species. Early work in this area showed that the absorptive capacity of leaves is related to the presence of polysaccharides under the cuticle (Kerstiens, 1996). However, the role of ubiquitous compounds of the cell walls, such as pectins and glycoproteins, on foliar water uptake has received little attention (Boanares et al., 2018). It is not known whether trichomes or sclerenchymatous structures display such hygroscopic compounds.

This knowledge gap is particularly severe for xerophylous species, which have leaves with abundant sclerenchymatous tissues, such as idioblasts, highly specialized structures that are understudied from a functional perspective. Idioblasts (Schwendener, 1874) are thick walled cells typically buried in the mesophyll of vascular plants (Bailey \& Nast, 1945; Tomlinson \& Fisher, 2005), and commonly found in the leaves of xerophilous species (Foster, 1956; Heide Jorgensen, 1990). Traditionally, idioblasts have been explored from the perspective of morphology, ontogeny, and taxonomic value (Foster,1944; 1945a,b; Bloch, 1946; Foster, 1955a,b; Rao \& Mody, 1961). However, important functions attributed to idioblasts are typically inferred from their putative stiffness, such as support and defense (Foster, 1947; Tucker, 1964; Rao \& Sharma, 1968), or from their topology, such as a possible role in leaf capacitance (Heide-Jorgensen, 1990) or serving as light guides (Karabourniotis, 1998). The diverse array of anatomies of xerophilous species is exemplified in the genus Capparis (Rao \& Mody, 1961; Gan et al., 2013). Capparis odoratissima is native to the semiarid tropical environments of the South American continent with a remarkable capacity to produce new biomass in response to canopy irrigation (Díaz \& Granadillo, 2005), likely through foliar water uptake. However, the mechanism of foliar water uptake in this species is unknown.

Here we focus on $C$. odoratissima with the goal of understanding the relationship between anatomy and function. We show that the leaves of $C$. odoratissima are highly specialized structures that perform a dual function: minimizing water loss when dry and absorbing water when wet. We examine how an intricate network of hygroscopic pathways within the mesophyll enhances water uptake, thus maintaining leaf hydration upon water condensation on the leaf surface.

\section{MATERIALS AND METHODS}

\subsection{Plant material}

Leaf material was obtained from Capparis odoratissima trees growing near the University of Francisco de Miranda in the state of Falcón, Venezuela.

\subsection{Evaluation of the external leaf morphology}

Five-to-six fully expanded leaves were scanned (along with a scale) using a CANON CanoScan LiDE 400 scanner, and leaf areas calculated using Image J1.51d software (National Institutes of Health, Bethesda, MD, USA). These same leaves were then used to photograph the details of both adaxial and abaxial surfaces with a Zeiss Discovery v12 Dissecting microscope (objective 0.63x PanApo). Adaxially, the idioblast tips were easily visualized by their translucency, and, abaxially, the peltate hairs were counted using their central parts as references. Both idioblasts and peltate hairs were counted in $1 \mathrm{~mm}^{2}$ areas at five positions on each leaf surface. To count the number of stomata, five leaves were fixed in FAA (formalin:acetic acid, Johansen 1940), washed three times in distilled water for one hour each, stained with Feulgen reaction (modified from Barell \& Grossniklaus, 2005). Then, the leaves were cleared with a solution containing ethanol:benzoyl benzoate $3: 1(\mathrm{v} / \mathrm{v})$ for six hours, ethanol:benzoyl benzoate 1:3 (v/v), and finally benzoyl benzoate: dibutyl pftalate 1:1 (v/v) for several days (Crane \& Carman, 1987). Following removal of the peltate hairs, $1 \mathrm{~mm}^{2}$ samples were imaged with a Zeiss LSM700 Confocal Microscope connected to an AxioCam 512 camera and Zen Blue 2.3 software, using a 20x/0.8 M27 Plan-Apochromat objective. Note that the area occupied by the rounded base of the peltate hairs $(3.45 \%)$ never contained stomata, and hence was subtracted from the total leaf area to get a more accurate estimate of stomatal density. 


\subsection{Evaluation of the internal leaf anatomy: idioblast characterization}

To better understand the structure of the idioblasts in the mesophyll, hand-cut transverse thin sections (perpendicular to the leaf surface) were made and stained with a solution of $0.01 \% \mathrm{w} / \mathrm{v}$ calcofluor white in $10 \mathrm{mM}$ CHES buffer with $100 \mathrm{mM} \mathrm{KCl}(\mathrm{pH}=10)$ (Hughes \& McCully, 1975), to identify cellulose-rich walls, and then with Auramine-O in $0.05 \mathrm{M}$ Tris/HCl buffer, $(\mathrm{pH}=7.2)$, to detect cutinized lipids (HeslopHarrison \& Shivanna, 1977). These sections were visualized with a Zeiss Axioskop microscope equipped with epifluorescence, and imaged with an AxioCam HRc camera, operated by Zen Blue software with multichannel wavelength detection. For calcofluor white, we used a DAPI narrow (Zeiss 48702) excitation G 365, bandpass $12 \mathrm{~nm}$; dichroic mirror FT 395; barrier filter LP397; for auramine O, we used an AF488/FITC/GFP (Zeiss Filter set 9) excitation 450-490; dichroic mirror 510; emission filter LP515. We isolated the idioblasts by macerating $1 \mathrm{~mm}^{2}$ leaf pieces in a solution containing acetic acid: hydrogen peroxide $1: 1(\mathrm{v} / \mathrm{v})$ at $60^{\circ} \mathrm{C}$ for 2 days. The debris of these samples was then mounted in distilled water or glycerol and visualized with a Zeiss LSM700 Confocal Microscope. 3D images were obtained without staining with the Objective: 63x/1.40 Oil DIC M27 Plan-Apochromat.

Samples obtained from five previously fixed leaves in FAA were washed in distilled water three times, $1 \mathrm{~h}$ each, and dehydrated with an increasing gradient of aqueous ethanol concentrations $(10 \%, 30 \%, 50 \%$, $70 \%, 100 \%$ (x3)). They were then soaked in the infiltration solution of Technovit7100 (Electron Microscopy Sciences, Hetfield, PA, USA) for several weeks, and polymerized under anoxic conditions. Blocks with samples oriented parallel to the leaf surface (paradermal) were serially sectioned at $4 \mu \mathrm{m}$ with a Leica RM2155 rotary

microtome (Leica Microsystems, Wetlar, Germany). Sections were then stained with an aqueous solution of $0.025 \%$ toluidine blue for general structure of the leaf tissues (Feder \& O'Brien, 1968), and finally imaged with a Zeiss AxioImager A2 Upright microscope equipped with an AxioCam 512 camera and Zen Blue Pro with multichannel software.

\subsection{Water and dye uptake experiments}

We first monitored epidermal transpiration in ten fully expanded leaves by letting them dry with their petiole covered with parafilm at room temperature (average $23 \pm 3^{\circ} \mathrm{C}$ ) and $30 \pm 3 \%$ of relative humidity (RH), weighing them every two hours with a four-digit precision scale. We then divided the weights by the leaf projected area (x2), fitted the temporal loss of each leaf weight to a linear regression function for the initial 10 hours, and averaged the slopes. This value served as a reference of epidermal evaporation from both leaf sides (slope $=-0.041 \mathrm{mg} \mathrm{cm}^{-2} \mathrm{~h}^{-1}$, average ${ }^{2}=0.95$ ). After that, we calculated the relative leaf water content (RWC) using the formula $\mathrm{RWC}=\left[\left(\mathrm{FW}_{\mathrm{t}}-\mathrm{DW}\right) /\left(\mathrm{FW}_{0}-\mathrm{DW}\right)\right]$, were $\mathrm{FW}_{\mathrm{t}}$ is the fresh weight at time $\mathrm{t}$, DW is the dry weight, and $\mathrm{FW}_{0}$ is the fresh weight at time 0 (Figure $5 \mathrm{a}$ ). We further calculated the initial water content of the leaves (Wi) as the difference between the fresh weight minus the dry weight per unit leaf area.

To estimate maximum rates of foliar uptake, five leaves were weighed $\left(\mathrm{Wt}_{0}\right)$ before being submerged in distilled water, with the petiole sealed, but not submerged, for $15 \mathrm{~min}$ (wet cycle). To eliminate any surface water, these leaves were centrifuged at $1800 \mathrm{rpm}$ for 2 min using a Sorvall RC6 Ultracentrifuge, and immediately weighed with a precision scale $\left(\mathrm{Wt}_{1}\right)$. Leaves were left to dry at room temperature for 15min (dry cycle) and weighed again before immersion $\left(\mathrm{Wt}_{2}\right)$. The cycle was repeated five times.

To understand the possible contribution of each surface to foliar water uptake, five leaves were loaded with $350 \mu \mathrm{L}$ of distilled water $(350 \mathrm{mg})$ evenly distributed in 35 droplets $(10 \mu \mathrm{L}$ each) covering roughly $25-30 \%$ of one surface, five leaves loaded on the abaxial side, and five loaded on the adaxial surface. When the droplets disappeared from the surfaces, the leaves were weighed with a precision scale, loaded again with the same amount of water, and this cycle repeated. Droplet disappearance was faster from the abaxial leaf surface, resulting in more time points during the 10 hours of the experiment.

To calculate water absorbed by each surface, we used the following formula for each cycle

$\mathrm{ABS}_{\mathrm{t}}=\left[\left(\mathrm{W}_{\mathrm{t}}-\mathrm{W}_{\mathrm{t} 0}\right)-\left(\mathrm{EP}_{\mathrm{t}} \mathrm{L}_{\mathrm{A}} *\left(\mathrm{t}-\mathrm{t}_{0}\right)\right)\right] / \mathrm{L}_{\mathrm{A}},(1)$,

where ABSt is the water absorbed, measured in $\mathrm{mg} \mathrm{cm}^{-2}$, at time $\mathrm{t}$ (after droplet disappearance from the 
surfaces), $\mathrm{W}_{\mathrm{t}}$ is the weight of the leaves in $\mathrm{mg}, \mathrm{L}_{\mathrm{A}}$ the leaf exposed area (the projected area of the unloaded surface plus $70 \%$ of the loaded one), $\mathrm{L}_{\mathrm{A}}$ is the projected leaf area (only one surface) measured in $\mathrm{cm}^{2}$, and $\mathrm{W}_{\mathrm{t} 0}$ the initial weight of the leaves in $\mathrm{mg}$. $\mathrm{EP}_{\mathrm{t}}$ is the epidermal transpiration rate of the leaf surface not covered by droplets (one side plus $70 \%$ of the other), which assumes that water loss from the two sides occurs at the same rate: $\mathrm{EP}_{\mathrm{t}}=-0.035 \mathrm{mg} \mathrm{cm} \mathrm{ch}^{-2}$.

To understand the pathways of water uptake, we used a $1 \%$ aqueous solution of the apoplastic fluorescent dye tracer Lucifer Yellow (LY; CH dilithium salt; Sigma). Dye (10 $\mu \mathrm{L}$ droplets) was applied to either the adaxial or the abaxial surfaces within a humidified chamber. We waited until the droplets disappeared from the surface, and then used a paper tissue to wipe any traces of the dye from the leaf surface prior to making transverse sections with a double edge razor blade. Sections were mounted in an aqueous solution of $70 \%$ glycerol, and immediately observed with a Zeiss LSM700 Confocal Microscope (wavelength 488nm). Similar sections of the same leaves, but in areas without the dye, were used as negative controls.

We further evaluated the rate of water and dye uptake by each leaf sidein vivo, applying $5 \mu \mathrm{L}$ droplets to the leaves of a seedling, and then taking images every five seconds (Videos S1-S4).

\subsection{Immunolocalization of pectin and arabinogalactan glycoprotein epitopes}

A preliminary test with the general dye Ruthenium red was used in freshly dissected leaves (Supplementary Figure 1) to evaluate the presence of neutral pectins (Colombo \& Rascio, 1977). Similarly, a preliminary test for arabinogalactan protein (AGP) presence was applied to cleared leaves with a $2 \%$ solution of the chemical reagent beta glucosyl Yariv reagent in $0.15 \mathrm{M} \mathrm{NaC} 1$ (Yariv, 1967). The $\beta$-GlcYR reacts with arabinogalactan proteins giving a red color upon precipitation (Supplementary Figure 2).

To identify the presence of pectic and AGP epitopes in the leaves of Capparis odoratissima, two monoclonal antibodies that detect highly un-esterified homogalacturonans (JIM5) and AGPs (JIM8) (Carbosource services, Georgia, USA) were used. Transverse and paradermal sections ( $4 \mu \mathrm{m}$ thick) of embedded leaves were incubated with 1XPBS 3x for five minutes each, followed by $5 \%$ bovine albumin serum (BSA) for five more minutes, and finally the undiluted primary monoclonal antibody for $45 \mathrm{~min}$. The sections were then washed three times in 1XPBS, five minutes each, and incubated again with an anti-Rat secondary antibody Alexa 488 conjugated with a fluorescent compound Fluorescein Isiothianate for one hour. Three final washes with 1XPBS preceded observations with a confocal microscope. Negative controls were treated in the same way, but substituting the primary antibody with a solution of $1 \%$ BSA in PBS.

\section{RESULTS}

\subsection{External leaf morphology of Capparis odoratissima}

Detailed evaluations of the oblong, hypostomatous leaves of $C$. odoratissima showed a dark green color of the adaxial surface (Figure 1a). Numerous translucent spots were located in concave areas of the surface, which corresponded with the tips of individual idioblasts (Figure 1b). Idioblast tips were interspersed between epidermal cells and, after staining and clearing the tissue, displayed a star-like shape when observed from above (Figure 1c). At higher magnification, each idioblast projected a narrow pore toward the adaxial surface of the leaf (Figure 1d). Abaxially, the leaves exhibited a pale green color (Figure 1e), which resulted from the total coverage of the lamina by an imbricate carpet of peltate hairs (Figure 1f). These non-glandular hairs were variable in size, but each contains a uniform multicellular, umbrella-like base, with thick-walled filiform cells (Figure 1g), and a central domed shield on top that protrudes to the exterior. Despite having very thick walls, there are interconnections between the central channels of the cells (Figure 1h).

\subsection{Leaf anatomy of Capparis odoratissima: cuticles, peltate hairs and idioblasts.}

Leaf cross-sections revealed that the idioblasts are thick-walled columnar structures that connect the adaxial and the abaxial surfaces (Figure 2a, drawn by Metcalfe \& Chalk, 1950). Idioblasts did not stain for lipids, but auramine $O$ staining revealed a thick cuticle layer on the adaxial surfaces of the leaves (Figure $2 \mathrm{~b}$ ), which was thinner in the concave depressions on top of the idioblasts. In contrast, the thick columnar walls 
of the idioblasts stained intensely with calcofluor white (Figure 2c) indicating the presence of cellulose in the thick walls, while staining with phloroglucinol indicated partial lignification. The abaxial surface of the leaf showed a thinner but rugose cuticle under the peltate hairs (Figure 2d). At the anchoring areas of the peltate hairs, the abaxial epidermis accumulated thick lipidic deposits (Figure 2e).

Idioblasts exhibited a bipolar pattern from the adaxial to the abaxial side of the leaf (Figure 3a). A thin projection that protruded apoplastically between the cells of the upper epidermis connected with the surface, and was sustained underneath with four-to-five filiform anchors attached to the base of the epidermal cells (Figure 3b). In the area of the palisade parenchyma, the idioblasts had a columnar shape, with a thick wall, narrow lumen, and crenations that connected the lumen with the palisade parenchyma (Figure 3c). In the spongy mesophyll, the irregular shape of idioblasts was characterized by numerous protuberances and crenations that connected the lumen of the idioblasts with adjacent mesophyll cells (Figure 3d). Closer to the abaxial side of the leaf, the idioblasts became thinner, as well as anastomosed and converged toward the base of the peltate hairs, maintaining narrow channels that connected the lumen of the idioblast with the lumen of the peltate hair (Figure 3e). On average, four idioblasts were connected to each peltate hair (Figure 4), whereas the frequency of abaxial stomata under the peltate hairs was significantly lower than that of idioblasts.

\subsection{Leaf water uptake in Capparis odoratissima}

The initial water content of detached leaves was approximately $9.5 \mathrm{mg} \mathrm{cm}^{-2}$. Weight loss of leaves exposed to lab conditions was used to understand epidermal evapotranspiration (Supplementary figure1). Leaf water content remained higher than $80 \%$ during the first 21 hours of exposure at low humidity, but then decreased sharply, with leaves becoming brittle 143 hours after the initial measurements. The epidermal water loss rate over the first 10 hours was $0.041 \mathrm{mg} \mathrm{cm}^{-2} \mathrm{~h}^{-1}$.

Leaves of Capparis odoratissima submerged for 15 minutes (wet cycle) absorbed water at a rate of $0.30 \mathrm{mg}$ $\mathrm{cm}^{-2} \mathrm{~h}^{-1}$. Rates of water loss during the dry cycle averaged $0.27 \mathrm{mg} \mathrm{cm} \mathrm{cm}^{-2} \mathrm{~h}^{-1}$, approximately seven times larger than epidermal water loss rates of leaves allowed to dry over a period of many hours. The water retained following each dry cycle (i.e. not evaporated) increased at a rate of $0.013 \mathrm{mg} \mathrm{cm}^{-2} \mathrm{~h}^{-1}$ (Fig. 5a), suggesting that evaporative losses became smaller with each cycle $\left(r^{2}=0.97\right)$.

The contribution of adaxial and abaxial leaf surfaces to water uptake was evaluated by loading each surface individually with water droplets (Figure 5b). Comparing the proportional weight variation over time revealed that even though only $30 \%$ of one surface was covered with water, the leaves significantly reduced their evaporative losses. However, there was a clear asymmetry: leaves loaded on the adaxial surface reduced their proportional water losses twofold with respect to the unloaded leaves, whereas leaves loaded on the abaxial surface reduced their evaporative losses almost six times. While this indicates that both surfaces can absorb water, water uptake by the abaxial surface is approximately three times larger $\left(0.033 \mathrm{mg} \mathrm{cm}^{-2} \mathrm{~h}^{-1}, r\right.$ ${ }^{2}=0.84$ ) relative to water absorption by the adaxial surface. These data suggest that loading each surface with the same amount of water results in different absorption capacities, but water absorption depends on the capacity to uptake water by each surface, but also on the epidermal evaporation of each unloaded surface, likely higher in the abaxial side, although this needs further testing.

\subsection{The pathways of leaf water uptake in Capparis odoratissima}

Dye loading onto the abaxial surface resulted in uptake that we believe was mediated by the central anchoring area of the peltate hairs (Figure 6a) due to the intense staining that remained in the thick walls of this central area of the peltate hairs after dye absorption (Figure 6b, Videos S2-S3). Fluorescence was further observed in the mesophyll of the leaves when dye was loaded onto either the adaxial or the abaxial surface, pointing to the dual role of the leaf surfaces in water uptake. Strikingly, the structures which retained the dye the most were the walls of the idioblasts, compared with a lack of fluorescence in these structures at the areas of the leaf without dye, which were used as negative controls (Figure 6c-d). The lumen of the idioblasts also became filled with the fluorescent dye, including the crenations (Figure 6e-f), revealing them as the bridges of water uptake from the leaf surface to the mesophyll. 


\subsection{Pectins and arabinogalactan proteins in the leaves of Capparis odoratissima}

Immunolocalization of pectin and arabinogalactan protein epitopes with monoclonal antibodies showed a dual topological pattern. Pectin epitopes were present in the cell walls of both adaxial and abaxial epidermis (Figure 7a-b), as roughly detected in fresh samples with ruthenium red Supplementary Figure 1a), in the external walls of the cells composing the spongy mesophyll (Figure 7c), and the external cell walls of the peltate hairs (Figure 7d; Supplementary figure 1b), but not in the idioblasts. The presence of arabinogalactan proteins was roughly detected with the beta glucosyl Yariv Reagent, which showed an intense red color in areas with idioblasts (Supplementary Figure 2). More specifically, the epitopes recognized by the JIM8 monoclonal antibody labelled a narrow area that corresponded with the lumen of the idioblasts, from their adaxial projection (Figure 7e), through the columnar lumen in the palisade parenchyma (Figure 7f), to the lumens of the anchoring areas of the peltate hairs (Figure 7g). As a result, AGPs coated the continuum of lumens between the peltate hairs and idioblasts.

\section{DISCUSSION}

\subsection{Water balance and leaf permeability in Capparis odoratissima}

Previous studies of $C$. odoratissima showed that, unlike other species coexisting in the same environment, C. odoratissimaincreased its biomass when the canopy, but not the soil, were supplied with water (Díaz \& Granadillo, 2005). However, the magnitude and pathway of water uptake by individual leaves was not quantified. Our detailed evaluations of water evaporation through time (i.e. epidermal evaporation), and entry of water (measured as the increase of leaf weight) from detached leaves serves to constrain the extreme values of water inputs and outputs. During the initial epidermal evaporation with the petiole sealed, water loss rates of $C$. odoratissima leaves were $0.041 \mathrm{mg} \mathrm{cm}^{-2} \mathrm{~h}^{-1}$, which results in a permeance $(P)$, calculated with the saturation concentration of water vapour at $20^{\circ} \mathrm{C}$ (according to Kerstiens, 1996), of $0.6610^{-5} \mathrm{~m} \mathrm{~s}^{-1}$. Compared with the 85 species for which the permeance was calculated from the mass loss of detached leaves, C. odoratissima leaves fall within the lowest ranges observed, similar to the values of species adapted to xeric environments such as Opuntia camanchica, with a $P$ value of $0.210^{-5} \mathrm{~m} \mathrm{~s}^{-1}$ (Pisek and Berger, 1938). Recent evaluations critically reviewed the meaning of permeances calculated by Kerstiens, pointing to a high variability of this parameter among species and biomes (Duursma et al., 2019). Our results suggest that the leaves of $C$. odoratissima retain water efficiently, although we could not be entirely sure that our leaves were initially saturated with water (our measurements started sometime after the leaves were detached). Furthermore, the dehydration rate of $C$. odoratissima leaves in natural conditions is likely slower than in our lab conditions, not only because the leaves are not detached, but also because the relative humidity of the atmosphere oscillates between 50\% and 90\% (Diaz \& Granadillo, 2005).

Capparis odoratissima leaves immersed in water increased in weight at a rate of $0.30 \mathrm{mg} \mathrm{cm} \mathrm{ch}^{-1}$, which is approximately seven times greater than rates of epidermal evaporation. The rate of water absorption by $C$. odoratissima leaves, however, is four times lower than in Tillandsia mullenbecki, which grows in the Atacama Desert in Chile, and is entirely dependent on foliar uptake (Raix et al., 2020). Nevertheless, we estimate that $15 \mathrm{~h}$ continuous exposure of the leaves to surface moisture may result in a $50 \%$ increase in leaf water content. Unlike in Tillandsia, we found that rates of water loss immediately following leaf immersion were large (on average $0.27 \mathrm{mg} \mathrm{cm}^{-2} \mathrm{~h}^{-1}$ ), and we interpret this as an evidence that water is weakly retained in the millions of interstices formed by the idioblasts, which were likely responsible for the high initial rate of water loss. The fact that leaves increased in weight over subsequent immersion and drying cycles demonstrates that water was being transferred to the mesophyll.

The major barriers for water absorption and/or evaporation are the leaf cuticles. Traditionally, the thickness of lipid coatings such as cuticles, were associated with higher water retention of leaves (Shields, 1950). Yet, the leaf cuticle is gradually revealing as a permeable layer to absorb water and electrolytes (Fernández et al., 2014; 2017). Thus, cuticle thickness may not have a direct relationship with impermeability (Schuster et al., 2017), but rather its biochemistry may be more important for water exchange between the mesophyll and the atmosphere. In our experiments, the leaves loaded adaxially gained less water than the ones loaded 
abaxially, pointing to a difference in absorption by each surface, and indirectly pointing to their different evaporative losses. The anatomy of leaves further played a role in these capacities, such as the compact and convoluted cuticle in the lower side of the leaves of $C$. odoratissima, which is thinner than that of the upper surface. Stomata embedded in this cuticle, despite being covered by a carpet of peltate hairs, which should reduce evapotranspiration, are probably ways of water scape. Pubescence is a typical character of xerophilous species, and functionally related with protection against desiccation and thus temperature regulation (Shields, 1950; Fahn, 1986). Future work is needed to explore the impact of the peltate hairs of the abaxial epidermis on reducing rates of water loss by stomata in vivo .

\subsection{Asymmetric foliar water uptake and anatomical specializations in Capparis odoratissima}

Our experiments with water droplets on each leaf surface revealed an asymmetry in the water uptake. Both surfaces of the $C$. odoratissima leaves loaded with water droplets showed an initial positive gain of water with time. However, when water was applied to the adaxial surface only, water gains were only possible for the initial six hours of exposure, and then water losses occurred. In contrast, when the abaxial surface was loaded, water uptake was linear, and followed a rate of $0.033 \mathrm{mg} \mathrm{cm}{ }^{-2} \mathrm{~h}^{-1}$, an order or magnitude lower than submerged leaves, due to evaporative losses of the exposed leaf surfaces. Previous work with the Australian subtropical species Sloanea woollsii (Yates and Hutley, 1995) showed similar rates for sprayed leaves, although these results were questioned by Kerstiens (1996), who suggested that small cracks in the cuticle could explain the extremely high leaf permeances. Natural openings (i.e. not created by microorganisms) are unusual in the upper leaf surface, except in amphistomous leaves, or leaves with hydathodes (Martin \& von Willert, 2000). However, we found thousands of micropores per $\mathrm{cm}$ area projecting toward concave areas on the adaxial leaf surfaces in Capparis odoratissima, which likely correlate with apoplastic water transport from the atmosphere to the leaf. These openings connect with the lumen of columnar idioblasts, pointing to these structures as significant players in the leaf water budgets.

Idioblasts have rarely been demonstrated as contributing to foliar water uptake in angiosperms, with some exceptions such as Hakea suaveolens (Heide-Jorgensen, 1990). However, their topology in the numerous forest species where they have been described, including gymnosperms (Hooker, 1864; Sterling, 1947), and more than eighty eudicot families (Solereder, 1908; Foster, 1955a,b; Rao \& Mody, 1961; Zhang et al., 2009; Vitarelli et al., 2016), suggested a role in the storage of water in leaves. As thick-walled sclerenchymatous tissues (Evert, 2006), idioblasts evolved multiple shapes and dispositions within leaves, but the columnar type of idioblasts displayed in the leaves of $C$. odortatissima have only been described in two species so far,Hakea suaveolens (Heide-Jorgensen, 1990), and Mouriria huberi (Foster, 1947). These adaptations cannot be related to xeric environments, as other species from the same genus and adapted to dry climates have completely different anatomies, such as the Mediterranean Capparis spinosa (Rhizopoulou, 1990; Rhizopoulou \& Psaras, 2003; Gan et al., 2013).

In nature, water condenses most likely on the adaxial surface of leaves, and, indeed, most studies of foliar water uptake suggest that the upper side is more permeable to water (Gardingen \& Grace, 1992; Fernández et al., 2014). In C. odoratissima, the reasons behind the asymmetric water uptake correlate with the markedly distinct anatomy between leaf surfaces. Although uptake from the adaxial surface is modest compared with the abaxial one, this dual possibility is unique among flowering plants. Indeed, this correlates with the unique anatomy of leaves, in which the lumen of the idioblasts formed a continuum with the peltate hairs located in the abaxial surface, traversing the cross sectional area of the leaves. As a result, an intricate network of micro channels linked both surfaces with the mesophyll. Trichome-idioblast associations are commonly found in species from arid environments such as those from the family Euphorbiaceae (Solereder, 1908; Metcalfe \& Chalk, 1950), Olea europaea (Arzeee, 1953), or Androstachys johnsoni(Alvin, 1987). The presence of peltate hairs is not indicative of foliar water uptake (Bickford, 2016), since species with peltate hairs such as in Olea europaea showed no evidence of water absorption (Arzeee, 1953). Our results revealed a high hygroscopicity of the peltate hairs of $C$. odoratissima. Hygroscopic peltate hairs have been reported in some angiosperm species (Gramatikopoulos \& Manetas, 1994; Bickford, 2016; Eller et al., 2016; Pina et al., 2016; Vitarelli et al., 2016), with the best studied being epiphytic bromeliads (Benzing \& Burt, 1970; Benzing, 1976; Benzing 
et al., 1978; Benz \& Martin, 2006; Ohrui et al., 2007; Raux et al., 2020). While a tradeoff between epidermal evaporation and water entrance from the atmosphere might exist, in $C$.odoatissima, this tradeoff favors the uptake of water from the trichomes of the lower surface, and from the idioblast tips when water condenses in the upper surface. Strikingly, loading the leaves of a seedling in vivo revealed that the droplet disappearance from the adaxial surface was similar to that of the abaxial one.

\subsection{The biochemistry of foliar water uptake in Capparis odoratissima}

The pathway of atmospheric water entry in the leaves of $C$. odoratissima involves hygroscopic materials deposited in the leaf coatings (Gouvra \& Gamatipoulus, 2003). In the current work, we first describe the thick walled structures composing the multicellular peltate hairs, which project pectins to the external part, suggesting their involvement in the initial water capture when condensation happens in the abaxial side. A few reports have revealed the presence of pectins in trichomes, such as species from semi-arid forests like Crombretum leprosum (Pina et al., 2016), the tropical species Drymis brasiliensis (Eller et al., 2013), or in the trichomes of Fagus(Schreel et al., 2020). In addition, we revealed that both epidermal and spongy mesophyll cells show a high concentration of un-esterified pectins in their cell walls. This is in line with the ubiquity of pectins within the leaf mesophyll. In the leaves of $C$. odoratissima, the tight association of mesophyll cells and their exposed pectins with the numerous idioblasts may imply a pulling force for water deposited on the leaf surfaces, using idioblasts as carriers.

The idioblasts of $C$. odoratissima are highly hygroscopic, with cellulosic walls that contain polar molecules for water attachment, but also partially lignified, suggesting a secondary role in defense and structural support. A finely tuned water uptake in $C$. odoratissima is revealed by our experiments with the apoplastic dye tracer Lucifer Yellow. Water entering from the surrounding atmosphere to the idioblasts flows through an intricate network of crenations and branches within the idioblasts that connect all leaf tissues and the exterior. Most strikingly is the fact that epitopes belonging to arabinogalacatan proteins are specifically located within these channels. AGPs are highly branched proteins with a short amino acid backbone attached to the plasma membrane of cells, and a large saccharidic part that has been related with nutritive and/or signaling functions between cells (Ellis et al., 2010). AGPs play different roles in plant development, including mate recognition and support during reproduction, proper early seedling development, and many others (Majewska-Sawka \& Nothnagel, 2000; Vaughn et al., 2007; Pereira et al., 2016). However, the role of AGPs in plant hydration has been scarcely studied. Remarkably, works evaluating the composition of the cell walls in the resurrection plant Craterostigma wilmsii, which can completely dry out and subsequently regain water, point to the hygroscopic properties of AGPs as critical players in this rapid and effective rehydration (Vicré et al, 2004). AGP-related proteins have been previously related with the tensile strength of stems due to their participation in secondary cell wall composition, such as in the vessels or fibers (Ito et al., 2005; Liu et al., 2013). But the presence of AGPs have never been reported before in idioblasts with such specific pattern as in the current work. What this reveals are the biochemical complexity of sclerenchymatous tissues, which are possible effectors enabling hydration of tissues during periods where water deficits in the soil combines with water saturation in the atmosphere (Figure 8). Thus, AGPs may be secreted to the lumen of the idioblasts during development, serving as bridges of water uptake between the atmosphere and the leaf mesophyll. Future works should explore the presence of AGPs in sclerenchymatous tissues of other species, as well as their putative role in leaf capacitance.

\section{CONCLUSIONS}

Leaf water absorption has been widely studied in the major groups of angiosperms, including magnoliids (eight genera), monocots (seven genera), and eudicots (67 genera) (reviewed by Berry et al., 2019, and by Dawson \& Goldsmith, 2018), pointing to foliar water uptake as a key factor affecting plant function in most ecosystems (Weathers et al., 2019). However, the effect of foliar hydration in the overall plant physiology is stronger in dry or semi-dry environments (Schreel et al., 2019), such as the dryland tropical areas where C. odoratissimagrows, where the water in the soil is often a limiting resource, and aerial water may become pivotal for plant growth and survival. 
Our data strongly suggest that the pathway for water uptake inCapparis odoratissima is mediated by the interconnected idioblasts and peltate hairs. We propose a model (Figure 8) that involves apertures of the leaves toward the adaxial surface, which are involved in water uptake, but may facilitate evapotranspiration. Hygroscopic materials belonging to arabinogalactan proteins serve to draw water into the lumen of the idioblasts, while pectins in the mesophyll and the epidermis may further facilitate the incorporation of water into leaf tissues. We believe that this cascade of biochemical and physical events underlies the ability of Capparis odoratissimatrees to utilize atmospheric water resources.

\section{Acknowledgements:}

We are grateful to Ned Friedman, Kea Wodruff, and Faye Rosin from the Arnold Arboretum of Harvard University for access to laboratory, greenhouse and imaging facilities. We thank Mr. Omar Fernando Sierra and Ms. E. Granadillo for help with plant material. Juan M. Losada is a ComFuturo Researcher at the IHSM-CSIC-UMA, funded by the Fundación General CSIC (FGCSIC), and within the project RTI2018102222A100. Miriam Diaz acknowledges a British Council Fellowship that allowed her to initiate this project while at the University of Cambridge and a Cisneros Fellowship the David Rockefeller Center for Latin American Studies that allowed her to continue this research at Harvard. This work was additionally supported by the National Science Foundation (EAGER 1659918, IOS 1456845 and DMR 14-20570).

\section{References:}

Aguirre-Gutiérrez, C. A., Holwerda, F., Goldsmith, G. R., Delgado, J., Yepez, E., Carbajal, N., EscotoRodríguez M., \& Arredondo, J. T. (2019). The importance of dew in the water balance of a continental semiarid grassland. Journal of Arid Environments , 168, 26-35.

Alvin, K. L. (1987). Leaf anatomy of Androstachys johnsonii Prain and its functional significance. Annals of Botany , 59(5), 579-591.

Arzeee, T. (1953). Morphology and ontogeny of foliar sclereids inOlea europaea . I. Distribution and structure. American Journal of Botany , 680-687.

Bailey, I. W., \& Nast, C. G. (1945). Morphology and relationships of Trochodendron and Tetracentron, I. Stem, root, and leaf.Journal of the Arnold Arboretum , 26(2), 143-154.

Barrell, P., \& Grossniklaus U. (2005). Confocal microscopy of whole ovules for analysis of reproductive development: the elongate1 mutant affects meiosis II. The Plant Journal 43, 309-320.

Benz, B. W., \& Martin, C. E. (2006). Foliar trichomes, boundary layers, and gas exchange in 12 species of epiphytic Tillandsia(Bromeliaceae). Journal of Plant Physiology , 163(6), 648-656.

Benzing, D. H. (1976). Bromeliad trichomes: structure, function, and ecological significance. Selbyana 1: $330-348$.

Benzing, D. H., \& Burt, K. M. (1970). Foliar permeability among twenty species of the Bromeliaceae. Bulletin of the Torrey Botanical Club , 269-279.

Benzing, D. H., Seemann, J., \& Renfrow, A. (1978). The foliar epidermis in Tillandsioideae (Bromeliaceae) and its role in habitat selection.American Journal of Botany , 65(3), 359-365.

Berry, Z. C., Emery, N. C., Gotsch, S. G., \& Goldsmith, G. R. (2019). Foliar water uptake: Processes, pathways, and integration into plant water budgets. Plant, Cell and Environment , 42(2), 410-423.

Berry, Z. C., White, J. C., \& Smith, W. K. (2014). Foliar uptake, carbon fluxes and water status are affected by the timing of daily fog in saplings from a threatened cloud forest. Tree Physiology , 34(5), 459-470.

Bickford, C. P. (2016). Ecophysiology of leaf trichomes.Functional Plant Biology , 43(9), 807-814.

Bloch, R. (1946). Differentiation and pattern in Monstera deliciosa. The idioblastic development of the trichosclereids in the air root.American Journal of Botany , 33(6), 544-551. 
Boanares, D., Ferreira, B. G., Kozovits, A. R., Sousa, H. C., Isaias, R. M. S., \& França, M. G. C. (2018). Pectin and cellulose cell wall composition enables different strategies to leaf water uptake in plants from tropical fog mountain. Plant Physiology and Biochemistry, 122, 57-64.

Boanares, D., Kozovits, A. R., Lemos-Filho, J. P., Isaias, R. M., Solar, R. R., Duarte, A. A., Vilas-Boas T., \& Franca, M. G. (2019). Foliar water-uptake strategies are related to leaf water status and gas exchange in plants from a ferruginous rupestrian field. American Journal of Botany , 106 (7), 935-942.

Breshears, D. D. McDowell N.G., Goddard K.L., Dayem K.E., Martens S.N., Meyer C., \& Brown K.M. (2008). Foliar absorption of intercepted rainfall improves woody plant water status most during drought.Ecology 89, 41-47.

Bickford, C. P. (2016). Ecophysiology of leaf trichomes.Functional Plant Biology , 43(9), 807-814.

Burkhardt, J., Basi, S., Pariyar, S., \& Hunsche, M. (2012). Stomatal penetration by aqueous solutions-an update involving leaf surface particles. New Phytologist , 196(3), 774-787.

Burgess, S. S. O., \& Dawson, T. E. (2004). The contribution of fog to the water relations of Sequoia sempervirens (D. Don): foliar uptake and prevention of dehydration. Plant, Cell and Environment, 27(8), $1023-1034$.

Choat, B., Jansen, S., Brodribb, T. J., Cochard, H., Delzon, S., Bhaskar, R., Bucci S., Feild T.S., Gleason S.M., Hacke U.G., Jacobsen A.L., Lens F., Maherali H., Martinez-Vilalta J., Mayr S., Mecuccini M., Mitchell P.J., Nardini A., Pittermann J., Pratt R.B., Sperry J.S., Westoby M., Wright I.J. \& Zanne A.E.. (2012). Global convergence in the vulnerability of forests to drought. Nature , 491 (7426), $752-755$.

Colombo, P. M., \& Rascio, N. (1977). Ruthenium red staining for electron microscopy of plant material. Journal of Ultrastructure Research , 60(2), 135-139.

Crane, C. F., \& Carman, J. G. (1987). Mechanisms of apomixis inElymus rectisetus from eastern Australia and New Zealand.American Journal of Botany , 74(4), 477-496.

Dawson, T. E., \& Goldsmith, G. R. (2018). The value of wet leaves.New Phytologist , 219(4), 1156-1169.

Diaz, M., \& Granadillo, E. (2005). The significance of episodic rains for reproductive phenology and productivity of trees in semiarid regions of northwestern Venezuela. Trees , 19(3), 336-348.

Duursma, R. A., Blackman, C. J., Lopez, R., Martin-StPaul, N. K., Cochard, H., \& Medlyn, B. E. (2019). On the minimum leaf conductance: its role in models of plant water use, and ecological and environmental controls. New Phytologist, 221(2), 693-705.

Eller, C. B., Lima, A. L., \& Oliveira, R. S. (2013). Foliar uptake of fog water and transport belowground alleviates drought effects in the cloud forest tree species, Drimys brasiliensis (W interaceae).New Phytologist , 199, 151-162.

Eller, C. B., Lima, A. L., \& Oliveira, R. S. (2016). Cloud forest trees with higher foliar water uptake capacity and anisohydric behavior are more vulnerable to drought and climate change. New Phytologist, 211(2), 489-501.

Ellis, M., Egelund, J., Schultz, C. J., \& Bacic, A. (2010). Arabinogalactan-proteins: key regulators at the cell surface? Plant Physiology , 153, 403-419.

Evert, R. F. (2006). Esau's plant anatomy: meristems, cells, and tissues of the plant body: their structure, function, and development. John Wiley \& Sons.

Fahn, A. (1986). Structural and functional properties of trichomes of xeromorphic leaves. Annals of Botany , 57, 631-637.

Feder, N. E. D., \& O'brien, T. P. (1968). Plant microtechnique: some principles and new methods. American Journal of Botany, 55, 123-142. 
Fernandez, V., Bahamonde, H. A., Javier Peguero-Pina, J., Gil-Pelegrin, E., Sancho-Knapik, D., Goldbach, H. E., Gil, L., \& Eichert, T. (2017). Physico-chemical properties of plant cuticles and their functional and ecological significance. Journal of Experimental Botany , 68, 5293-5306.

Fernandez, V., Sancho-Knapik, D., Guzman, P., Peguero-Pina, J. J., Gil, L., Karabourniotis, G., Khayet, M., Fasseas, C., Heredia-Guerrero, J. A., Heredia, A., \& Gil-Pelegrin, E. (2014). Wettability, polarity, and water absorption of holm oak leaves: effect of leaf side and age.Plant Physiology , 166, 168-180.

Foster, A. S. (1944). Structure and Development of sclereids in the petiole of Camellia japonica L. Bulletin of the Torrey Botanical Club , 71, 302-326.

Foster, A. S. (1945a). Origin and development of sclereids in the foliage leaf of Trochodendron aralioides Sieb. \& Zucc.American Journal of Botany, 32, 456-468.

Foster, A. S. (1945b). The foliar sclereids of Trochodendron aralioides sieb. \& zucc. Journal of the Arnold Arboretum , 26, 155-162.

Foster, A. S. (1947). Structure and ontogeny of the terminal sclereids in the leaf of Mouriria huberi Cogn. American Journal of Botany, 34(9), 501-514.

Foster, A. S. (1955a). Comparative morphology of the foliar sclereids inBoronella Baill. Journal of the Arnold Arboretum , 36, 189-198.

Foster, A. S. (1955b). Structure and ontogeny of terminal sclereids inBoronia serrulata . American Journal of Botany , 42, 551-560.

Foster, A. S. (1956). Plant idioblasts: remarkable examples of cell specialization. Protoplasma , 46, 184-193.

Franke, W. (1967). Mechanisms of foliar penetration of solutions.Annual Review of Plant Physiology , 18, 281-300.

Gan, L., Zhang, C., Yin, Y., Lin, Z., Huang, Y., Xiang, J., \& Fu, C. (2013). Anatomical adaptations of the xerophilous medicinal plant,Capparis spinosa, to drought conditions. Horticulture, Environment, and Biotechnology , 54, 156-161.

Gardingen, P. R. V., \& Grace, J. (1992). Vapour pressure deficit response of cuticular conductance in intact leaves of Fagus sylvatica L. Journal of Experimental Botany , 43, 1293-1299.

Grammatikopoulos, G., \& Manetas, Y. (1994). Direct absorption of water by hairy leaves of Phlomis fruticosa and its contribution to drought avoidance. Canadian Journal of Botany , 72, 1805-1811.

Gotsch, S. G., Asbjornsen, H., Holwerda, F., Goldsmith, G. R., Weintraub, A. E., \& Dawson, T. E. (2014). Foggy days and dry nights determine crown-level water balance in a seasonal tropical montane cloud forest. Plant, Cell and Environment, 37, 261-272.

Gouvra, E., \& Grammatikopoulos, G. (2003). Beneficial effects of direct foliar water uptake on shoot water potential of five chasmophytes. Canadian Journal of Botany , 81, 1278-1284.

Heide-Jorgensen, H. S. (1990). Xeromorphic leaves of Hakea suaveolens R. Br. IV. Ontogeny, structure and function of the sclereids. Australian Journal of Botany , 38, 25-43.

Heslop-Harrison, Y., \& Shivanna, K. R. (1977). The receptive surface of the angiosperm stigma. Annals of Botany , 41, 1233-1258.

Hughes, J., \& McCully, M. E. (1975). The use of an optical brightener in the study of plant structure. Stain Technology, 50, 319-329.

Ito, S., Suzuki, Y., Miyamoto, K., Ueda, J., \& Yamaguchi, I. (2005). AtFLA11, a fasciclin-like arabinogalactan-protein, specifically localized in sclerenchyma cells. Bioscience and Biotechnological Biochemistry , 69, 1963-1969. 
Johansen, D. A. (1940). Plant Microtechnique . McGraw-Hill Book, New York, USA.

Karabourniotis, G. (1998). Light-guiding function of foliar sclereids in the evergreen sclerophyll Phillyrea latifolia : a quantitative approach. Journal of Experimental Botany , 49, 739-746.

Kerstiens, G. (1996). Cuticular water permeability and its physiological significance. Journal of Experimental Botany , 47, 1813-1832.

Kreft, H., \& Jetz, W. (2007). Global patterns and determinants of vascular plant diversity. Proceedings of the National Academy of Sciences, 104, 5925-5930.

Limm, E. B., Simonin, K. A., Bothman, A. G., \& Dawson, T. E. (2009). Foliar water uptake: a common water acquisition strategy for plants of the redwood forest. Oecologia , 161, 449-459.

Liu D., Tu L., Li Y., Wang L., Zhu L., \& Zhang X. (2008). Genes encoding fasciclin-like arabinogalactan proteins are specifically expressed during cotton fiber development. Plant Molecular Biology Reporter 26, 98-113.

Liu, H., Shi, R., Wang, X., Pan, Y., Li, Z., Yang, X., Zhang G., \& Ma, Z. (2013). Characterization and expression analysis of a fiber differentially expressed Fasciclin-like arabinogalactan protein gene in Sea Island cotton fibers. PloS one, 8, e70185.

Majewska-Sawka, A., \& Nothnagel, E. A. (2000). The multiple roles of arabinogalactan proteins in plant development. Plant Physiology, 122, 3-10.

Colombo M.P., \& Rascio N. (1977). Ruthenium red staining for electron microscopy of plant material. Journal of Ultrastructure Research , 60, 135-139.

Martin, C. E., \& von Willert D.J. (2000). Leaf epidermal hydathodes and the ecophysiological consequences of foliar water uptake in species of Crassula from the Namib Desert in southern Africa. Plant Biology , 2, 229-242.

Mayr S., Schmid P., Laur J., Rosner S., Charra-Vaskou K., Damon B., \& Hacke U.G. (2014) Uptake of water via branches helps timberline conifers refill embolized xylem in late winter. Plant Physiology , 164, $1731-1740$.

Metcalfe, C. R., \& Chalk, L. (1950). Anatomy of the Dicotyledons 1 \& 2 . Clarendon Press. Oxford.

Nobel P.S. (2009). Physicochemical and Environmental Plant Physiology (4th edition). Elsevier Inc. New York.

Olson, M. E., Soriano, D., Rosell, J. A., Anfodillo, T., Donoghue, M. J., Edwards, E. J., Leon-Gomez C., Dawson T., Camarero Martinez J.J., Castorena M., Echeverria A., Espinosa C.I., Fajardo A., Gazol A., Isnard S., Lima R.S., Marcati C.R., Mendez-Alonzo R. (2018). Plant height and hydraulic vulnerability to drought and cold. Proceedings of the National Academy of Sciences, 115(29), 7551-7556.

Ohrui, T., Nobira, H., Sakata, Y., Taji, T., Yamamoto, C., Nishida, K., Yamakawa T., Yaguchi Y., Tanekaga H., Tanaka, S. (2007). Foliar trichome-and aquaporin-aided water uptake in a drought-resistant epiphyte Tillandsia ionantha Planchon. Planta, 227(1), 47-56.

Pereira, A. M., Lopes, A. L., Coimbra, S. (2016). Arabinogalactan proteins as interactors along the crosstalk between the pollen tube and the female tissues. Frontiers in plant science, 7, 1895.

Pina, A. L., Zandavalli, R. B., Oliveira, R. S., Martins, F. R., Soares, A. A. (2016). Dew absorption by the leaf trichomes of Combretum leprosum in the Brazilian semiarid region. Functional Plant Biology , 43(9), 851-861.

Pisek, A., \& Berger, E. (1938). Kutikulare Transpiration und Trockenresistenz isolierter Blatter und Sprosse. Planta , 28(1), 124-155. 
Rao, T. A., Mody, K. J. (1961). On terminal sclereids and tracheoid idioblasts. Proceedings of the Indian Academy of Sciences-Section B , 53(5), 257-262.

Rao, A. R., Sharma, M. (1968). The terminal sclereids and tracheids ofBruguiera gymnorhiza Blume and the cauline sclereids ofCeriops roxburghiana Arn. Proceedings of the Indian Academy of Sciences-Section B , 34(6), 267-275.

Raux, P.S., Gravelle, S. Dumais, J. (2020). Design of a unidirectional water valve in Tillandsia . Nature Communications, 11, 396, 1-7.

Rhizopoulou, S. (1990). Physiological responses of Capparis spinosa L. to drought. Journal of Plant Physiology , 136(3), 341-348.

Rhizopoulou, S., Psaras, G. K. (2003). Development and structure of drought-tolerant leaves of the Mediterranean shrub Capparis spinosa L. Annals of Botany , 92(3), 377-383.

Schreel, J. D., Leroux, O., Goossens, W., Brodersen, C., Rubinstein, A., Steppe, K. (2020). Identifying the pathways for foliar water uptake in beech (Fagus sylvatica L.): a major role for trichomes. The Plant Journal . doi.org/10.1111/tpj.14770.

Schreel, J. D., von der Crone, J. S., Kangur, O., Steppe, K. (2019). Influence of drought on foliar water uptake capacity of temperate tree species. Forests , 10(7), 562.

Schuster, A. C., Burghardt, M., Riederer, M. (2017). The ecophysiology of leaf cuticular transpiration: are cuticular water permeabilities adapted to ecological conditions? Journal of Experimental Botany , 68(19), $5271-5279$.

Shields, L. M. (1950). Leaf xeromorphy as related to physiological and structural influences. The Botanical Review , 16(8), 399-447.

Solereder, H. (1908). Systematic Anatomy of the Dicotyledons . Oxford.

Steppe K., Vandegehuchte M.W., van de Wal B,A,E, Hoste P., Guyot A., Lovelock C.E., Lockington D.A. (2018). Direct uptake of canopy rainwater causes turgor-driven growth spurts in the mangrove Avicennia marina. Tree Physiology, 38, 979-991.

Schwendener, S. (1874). Das mechanische Prinicip im aiiatomischen Bau der Moniocotylen.

Tognetti, R. (2015). Trees harvesting the clouds: fog nets threatened by climate change. Tree Physiology , $35(9), 921-924$.

Tomlinson, P. B., \& Fisher, J. B. (2005). Development of non-lignified fibers in leaves of Gnetum gnemon (Gnetales). American Journal of Botany , 92, 383-389.

Tucker, S. C. (1964). The terminal idioblasts in magnoliaceous leaves.American Journal of Botany , 51, 1051-1062.

Vaadia, Y., \& Waisel, Y. (1963). Water absorption by the aerial organs of plants. Physiologia Plantarum, $16,44-51$.

Vaughn, K. C., Talbot, M. J., Offler, C. E., \& McCurdy, D. W. (2007). Wall ingrowths in epidermal transfer cells of Vicia fabacotyledons are modified primary walls marked by localized accumulations of arabinogalactan proteins. Plant and Cell Physiology , 48, 159-168.

Vicre, M., Lerouxel, O., Farrant, J., Lerouge, P., \& Driouich, A. (2004). Composition and desiccationinduced alterations of the cell wall in the resurrection plant Craterostigma wilmsii .Physiologia Plantarum, 120, 229-239.

Vitarelli, N. C., Riina, R., Cassino, M. F., \& Meira, R.M. S. A. (2016). Trichome-like emergences in croton of Brazilian highland rock outcrops: evidences for atmospheric water uptake. Perspectives in Plant Ecology, 
Evolution and Systematics, 22, 23-35.

Weathers, K. C., Ponette-Gonzalez, A. G., \& Dawson, T. E. (2019). Medium, vector, and connector: fog and the maintenance of ecosystems. Ecosystems , 1-13. https://doi.org/10.1007/s10021-019-00388-4

Yates, D. J., \& Hutley, L. B. (1995). Foliar uptake of water by wet leaves of Sloanea woollsii , an Australian subtropical rainforest tree. Australian Journal of Botany , 43, 157-167.

Yariv J., Lis H., \& Katchalski, E. (1967). Precipitation of arabic acid and some seed polysaccharides by glycosylphenylazo dyes. The Biochemical Journal 105, 1C - 2C.

Zhang, W., Hu, Y., Li, Z., Wang, P., Xu, M. (2009). Foliar sclereids in tea and its wild allies, with reference to their taxonomy.Australian Systematic Botany, 22, 286-295.

\section{FIGURES AND LEGENDS}

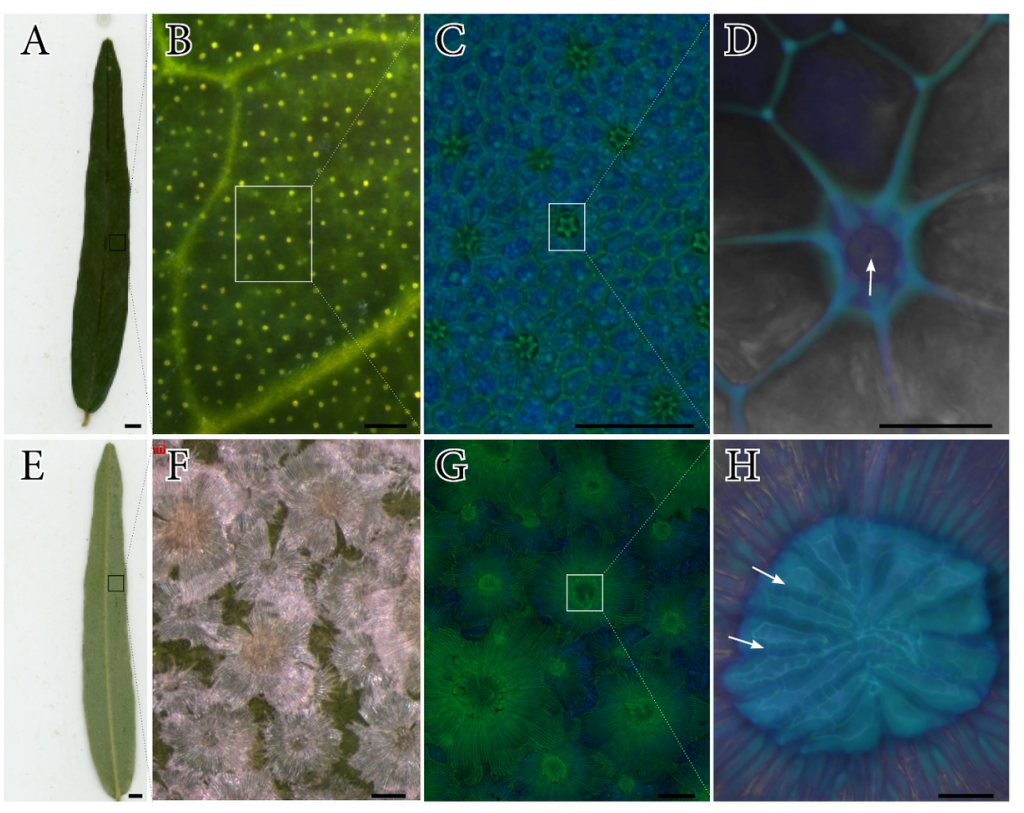

FIGURE 1. Leaf surface anatomy of Capparis odoratissima . (a) Elongated leaf shape with a dark green 
adaxial color. (b) Conspicuous pattern of translucent idioblast tips on adaxial leaf surface. (c) Cleared tissue showing a star-like appearance at the tip of these structures. (d) Closer view, showing a narrow pore (arrow) in the center of an idioblast. (e) Abaxial surface of the leaves with a pale green color. (f) A continuous layer of imbricate peltate hairs covers the abaxial surface. (g) Peltate hairs are composed of two parts: a central stalk surrounded by filiform projections. (h) In the center of each peltate hair, a compact dome of thick walled filiform structures further showed connections between their lumens (arrows). Dissecting scope images (a-d, adaxial; e-h, abaxial), and confocal images of cleared leaves stained with the Feulgen reaction (c,d, adaxial; g,h, abaxial).Scale bars: a,e $=500 \mu \mathrm{m} ; \mathrm{b}, \mathrm{f}=200 \mu \mathrm{m} ; \mathrm{c}, \mathrm{g}=100 \mu \mathrm{m} ; \mathrm{d}, \mathrm{h}=20 \mu \mathrm{m}$.
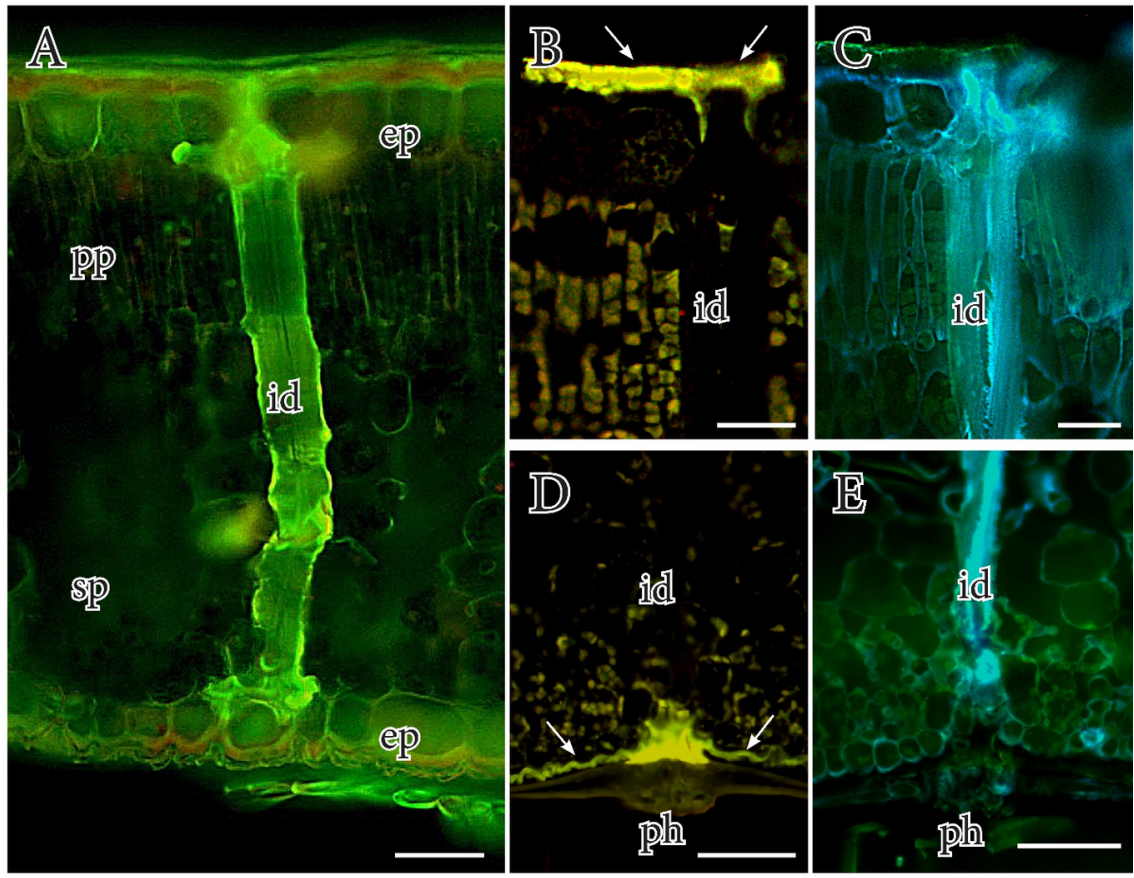

FIGURE 2. The internal anatomy of the leaves in Capparis odoratissima . (a) Cross-section of the leaf displaying autofluorescence of the numerous ididoblasts that traverse the mesophyll and connect the adaxial and abaxial leaf surfaces. (b) Thick cuticle layer (white arrowheads) on the adaxial epidermis of the leaf, but notably thinner above the idioblasts, stained with auramine $\mathrm{O}$ for cutin and lipids (yellow, arrows). (c) The thick walls of the idioblasts contain massive cellulose (stained with calcofluor white, blue color). (d) The cuticle of the abaxial surface (arrows) is thinner, rugose and accumulates massively at the base of the peltate hairs. (e) Idioblasts directly connect with the center of the peltate hairs. Ep, epidermis; pp, palisade parenchyma; id, idioblast; sp, spongy parenchyma; ph, peltate hair. Scale bars: a,d,e $=50 \mu m ; b, c=20 \mu m$. 

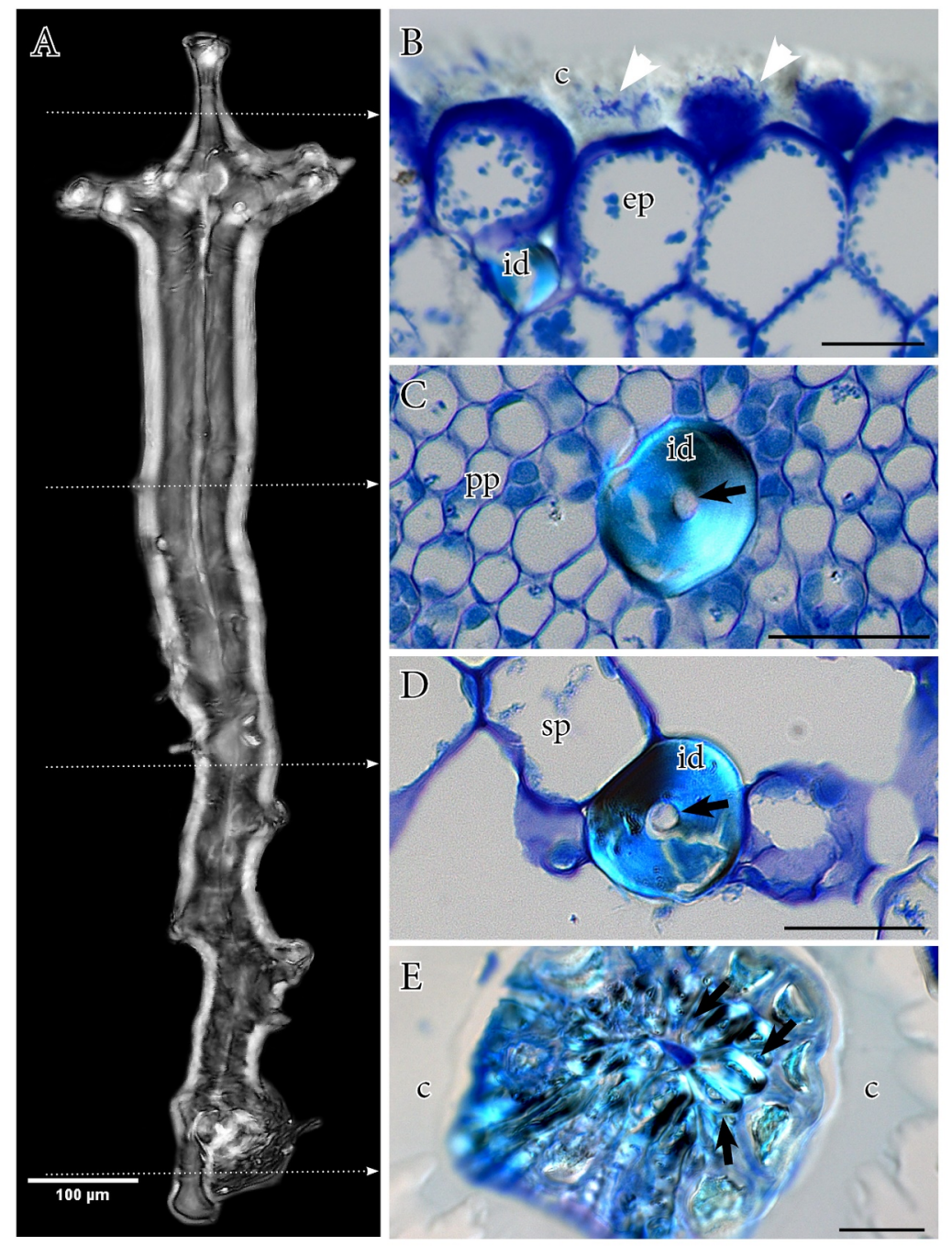

FIGURE 3. Characterization of the idioblasts of Capparis odoratissima . (a) Maximum 3D projection of an isolated idioblast showing their typical structure of a small tubular projection towards the adaxial epidermis (top) and irregular walls toward the abaxial surface. (b) Cells of the adaxial epidermis are thick and have substantial extracellular materials (blue color) that intersperse with the thick adaxial cuticle (white arrowheads). (c) The idioblasts are columnar within the palisade parenchyma, with thick refringent walls and narrow lumens (arrow). (d) At the level of the spongy mesophyll, numerous canals connect the idioblast lumen with the surrounding mesophyll cells. (e) At the abaxial epidermis, adjacent idioblasts anastomose and form an irregular structure that connects with the center of the peltate hairs. B-D semi-thin sections stained with toluidine blue for general structure. C, cuticle; ep, epidermis; pp, palisade parenchyma; id, idioblast; sp, spongy parenchyma; ph, peltate hair. Dotted arrows in A indicate the plane of section of images on the right. Scale bars: $a=100 \mu \mathrm{m} ; \mathrm{b}-\mathrm{e}=20 \mu \mathrm{m}$. 


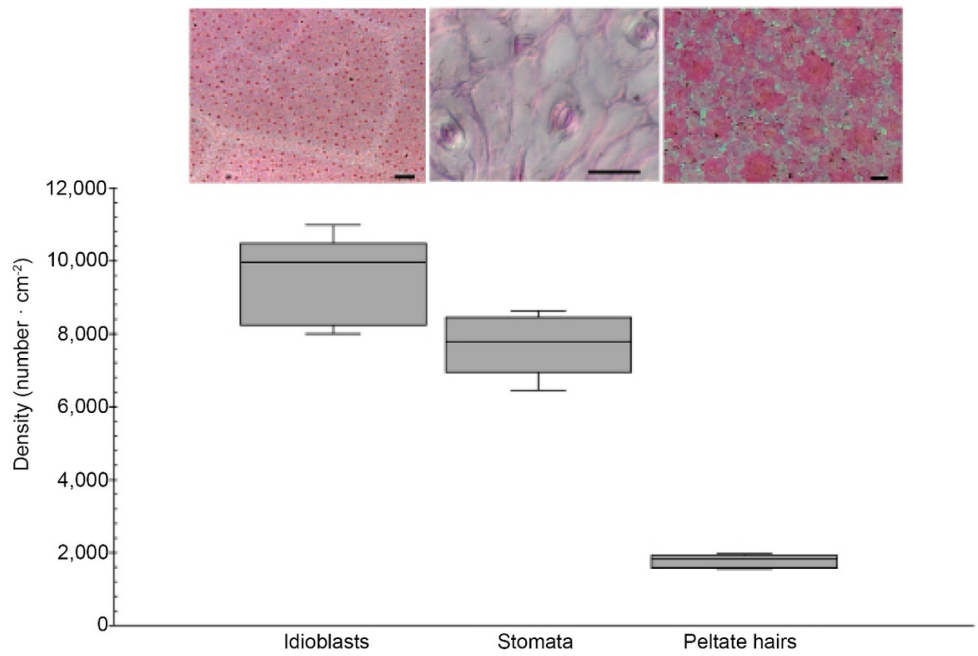

FIGURE 4. Frequency of idioblasts, stomata and peltate hairs in the leaves of Capparis odoratissima. Note that idioblasts (red dots in the first image) are more numerous than stomata (middle image). Interestingly, there are on average four to six times more idioblasts than peltate hairs (third image). Imaged display parts of the cleared leaves stained with Basic Fuchsin. Scale bars: $20 \mu \mathrm{m}$ 

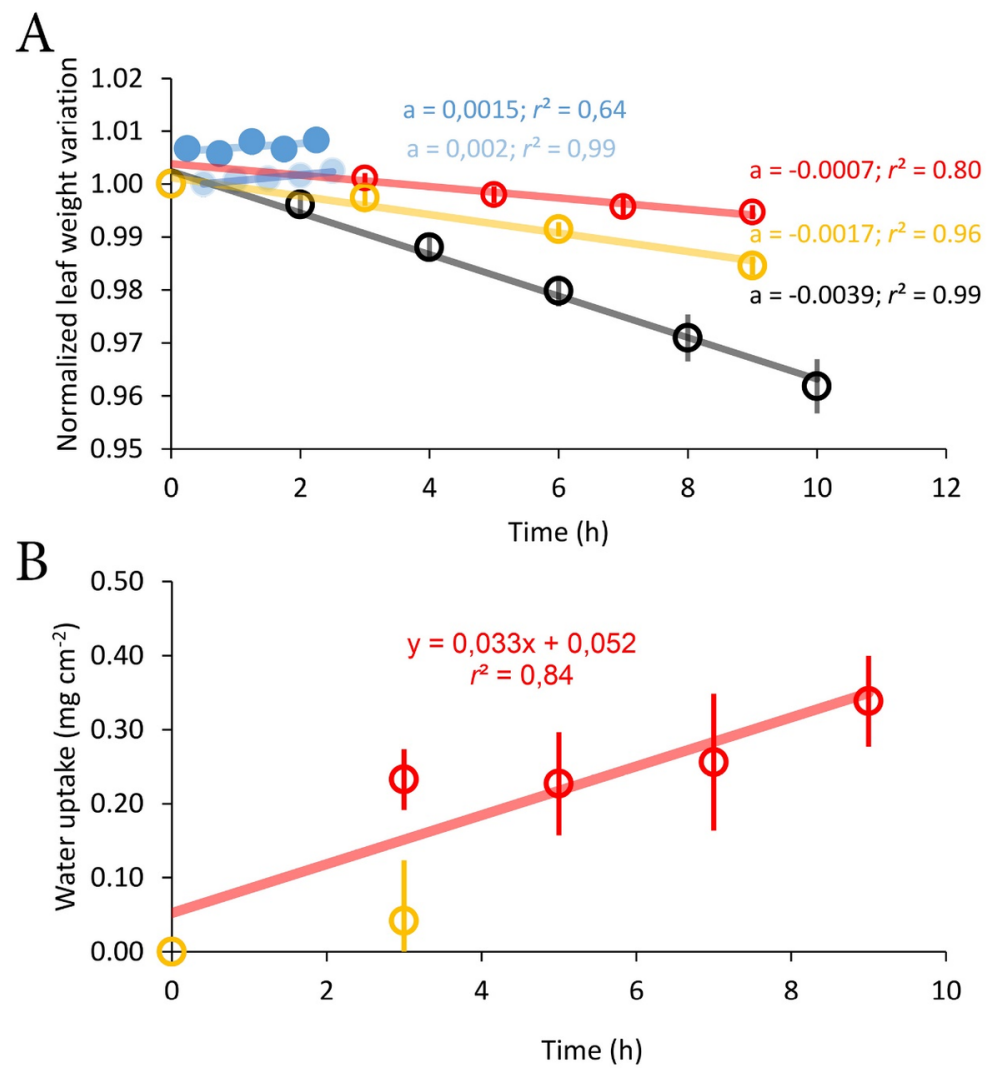

FIGURE 5 . Water budgets by leaves of Capparis odoratissima . (a) Normalized leaf weight variation (proportional to the initial leaf weight) of the leaves of Capparis odoratissimacomparing different treatments: blue filled dots represent the maximum weight increase of immersed leaves after the wet cycle (dark blue), and minimum weight variation after the dry cycles (light blue); note that both follow a linear positive rate over time. Empty circles represent weight loss under epidermal evaporation (black), when $30 \%$ of the adaxial surface was covered with droplets (yellow), and when $30 \%$ of the abaxial surface was covered with droplets (red). Slopes (a) are shown for comparison and have units of $\mathrm{h}^{-1}$. (b) Cumulative water uptake by leaves loaded on the adaxial (yellow) or the abaxial (red) surfaces. Bars represent standard errors at a $p$ [?]0.95. 

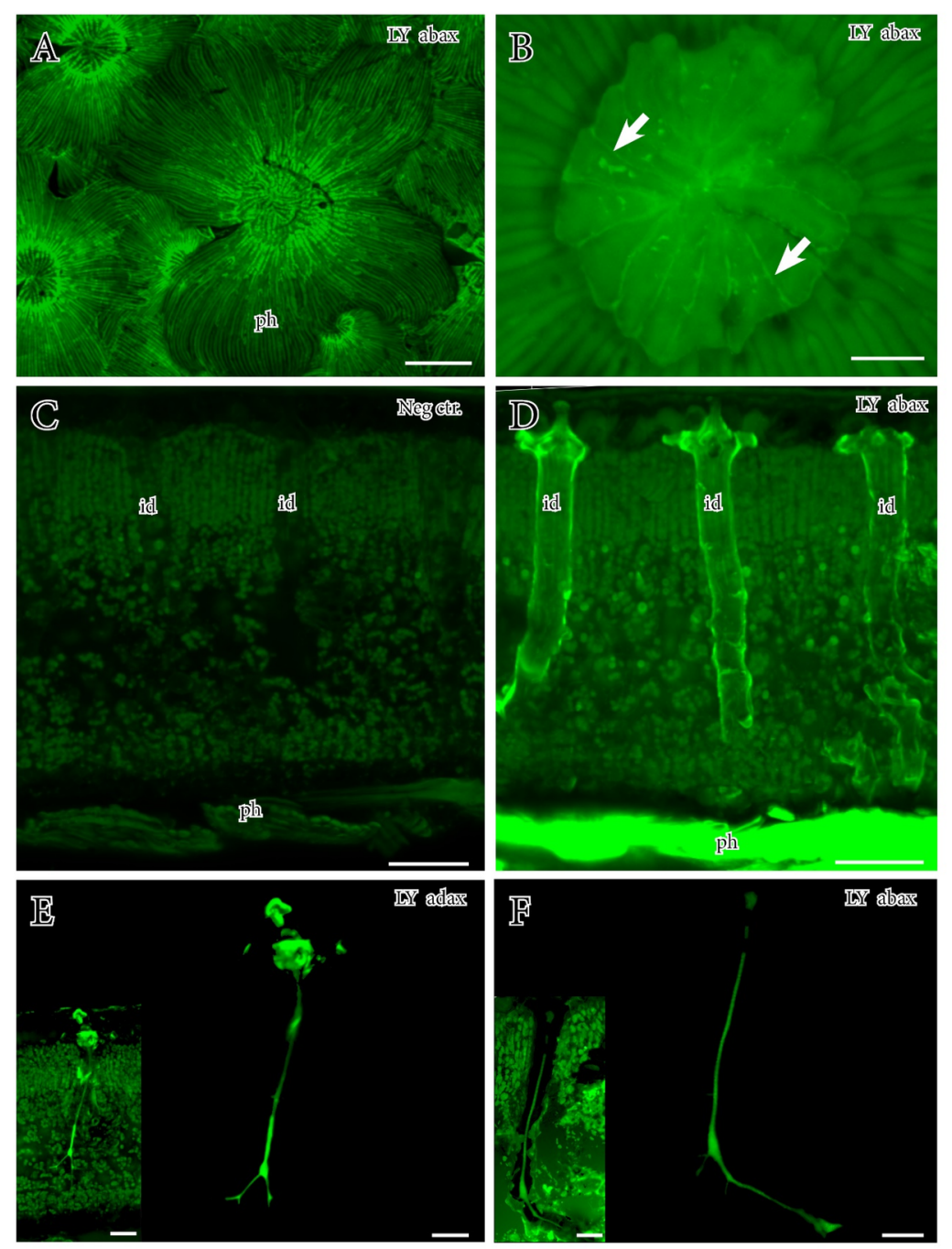

FIGURE 6. Fluorescent dye loading in the leaves of Capparis odoratissima. (a) Abaxial deposition of $1 \mu \mathrm{L}$ droplets LY revealed strong fluorescence towards the center of the peltate hairs. (b) Detail of the central region of the peltate hairs showing fluorescence in the cell walls (arrows). (c) Negative control showing absence of autofluorescence in the cell walls of the idioblasts with a $488 \mathrm{~nm}$ wavelength. (d) Following abaxial loading of the dye, idioblasts showed a strong fluorescence in their walls. (e) Maximum projection of the lumen of an idioblast filled with LY dye after adaxial deposition. (f) Same as E, but with the dye loaded abaxially. Id, idioblast. LY adax, adaxial load of Lucifer yellow; LY abax, abaxial load of Lucifer Yellow. Scale bars: $\mathrm{a}=100 \mu \mathrm{m} ; \mathrm{b}-\mathrm{f}=20 \mu \mathrm{m}$. 

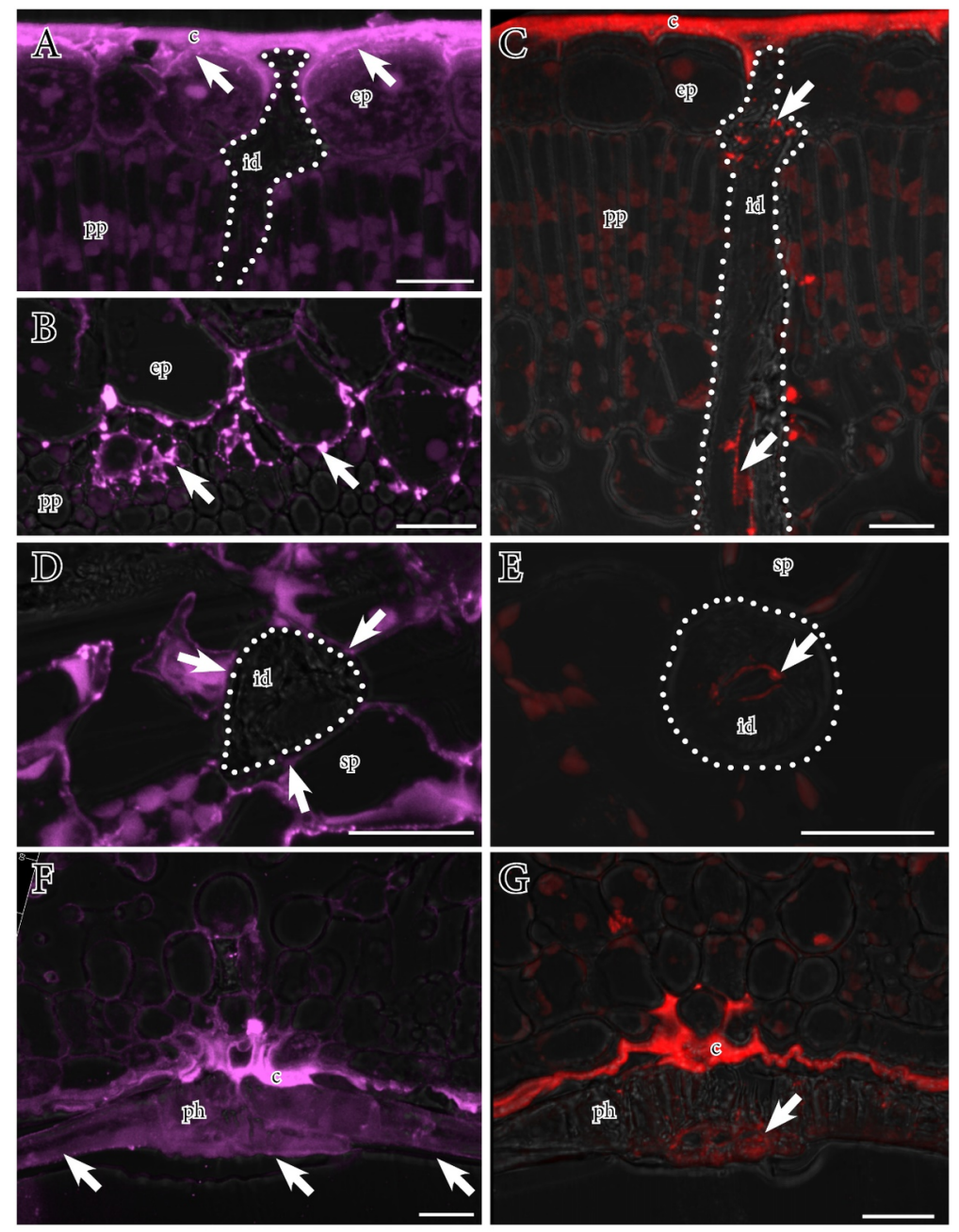

FIGURE 7. Immunolocalization of pectins (JIM7 mAb; purple color) and arabinogalactan proteins (JIM8 $\mathrm{mAb}$; red color) in Capparis odoratissima leaves in transverse ( $\mathrm{a}, \mathrm{c}, \mathrm{f}, \mathrm{g}$ ) and paradermal (b, d, e) sections. (a, b) High levels of pectins (arrows) were indicated in the apoplast of epidermal cells, particularly between the cuticle and the cell walls of the epidermis (dotted lines indicate the profile of an idioblast). (c) In contrast, AGPs epitopes (arrows) were present in the lumen of the idioblasts (dotted line). (d) Pectins (arrows) were also present in the external cell walls of the spongy mesophyll in contact with the idioblasts (dotted line). (e) Arabinogalactan protein epitopes (arrows) showed a consistent presence along the lumen of idioblasts (dotted line). (f) The external walls of the peltate hairs showed a consistent presence of pectins (arrows). (g) The lumens of the peltate hairs further contained AGPs (arrows), consistent with their presence along the idioblast-hair continuum. C, cuticle; ep, epidermis; pp, palisade parenchyma; id, idioblast; sp, spongy parenchyma; ph, peltate hair. Scale bars: $20 \mu \mathrm{m}$. 

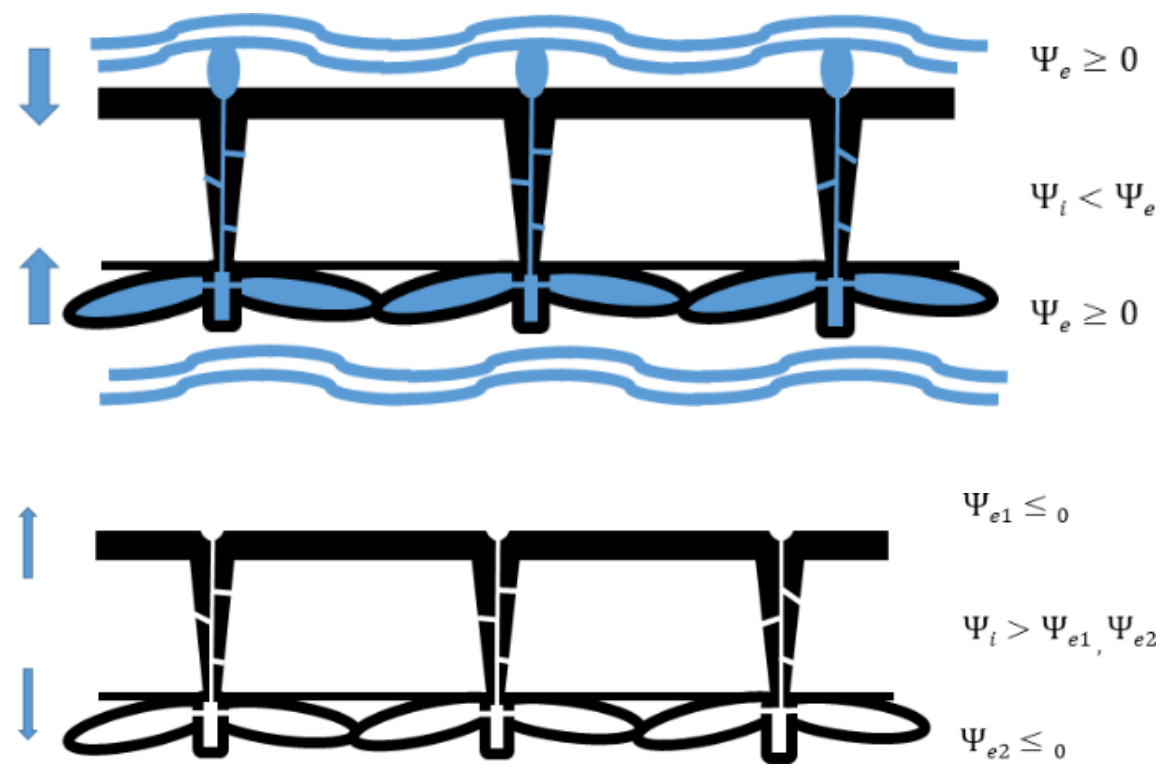

A B
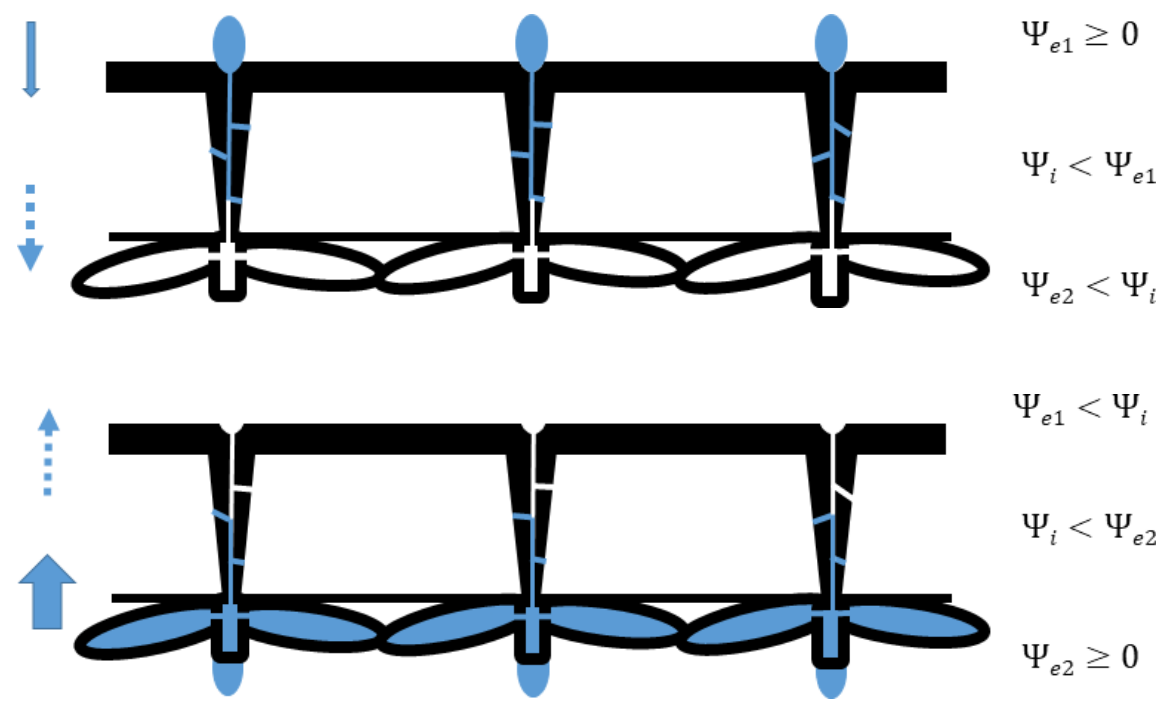

C D

FIGURE 8. Simplified model of water balance in the leaves of Capparis odoratissima . (a) In the absence of high humidity of the surrounding atmosphere, the water potential of the leaves is higher than the surrounding environment, thus there is a net loss of water (blue arrows). (b). The opposite situation happens with submerged leaves, which have lower water potentials than the environment, thus gaining water (blue arrows) through the lumen of the continuum peltate hairs-idoblasts. (c) When water condenses in the upper surface, the inner leaf potential is lower than this surface, thus allowing water to enter through the lumen of the idioblasts (blue arrow), while water losses from the lower surface (assuming a 'dry'environment) may equal water gains (dotted arrows). (d) When water condenses in the lower surface, water enters through the lumen of the peltate hairs and the idioblasts (thick blue arrow), but cuticular water loss through the upper leaf surface (assuming a 'dry'environment) appears to be lower than water entrance (thin blue arrow). 


\section{SUPPORTING INFORMATION}

Figure S1. Water loss percentage with time in bench-dried leaves of Capparis odoratissima .

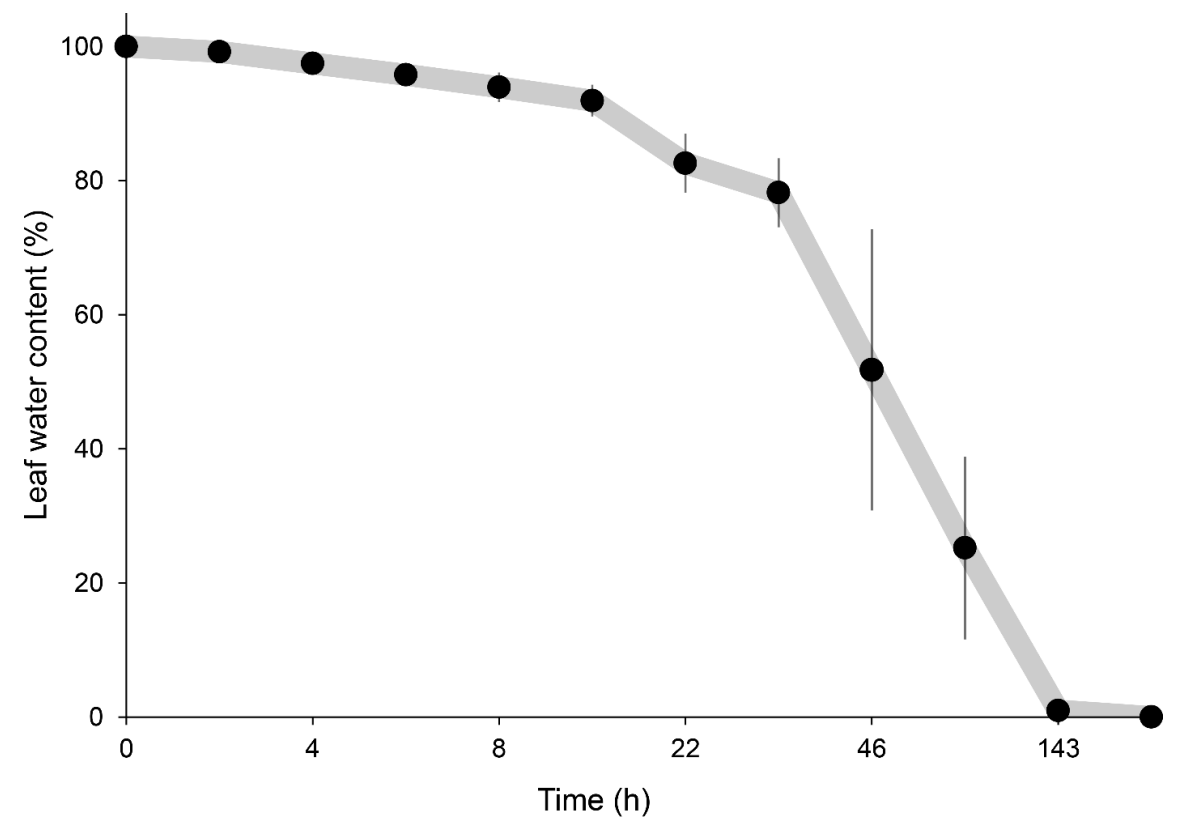

Figure S2: Localization of pectins (red color, yellow arrows) in leaf whole mounts of Capparis odoratissima . (a) Pectins localized the adaxial and abaxial epidermal cell walls, as well as in cells of the spongy mesophyll of freshly cut leaves (arrows). (b) The cell walls of the multicellular peltate hairs further stained for pectins (red color, arrows). Scale bars: 50um. 


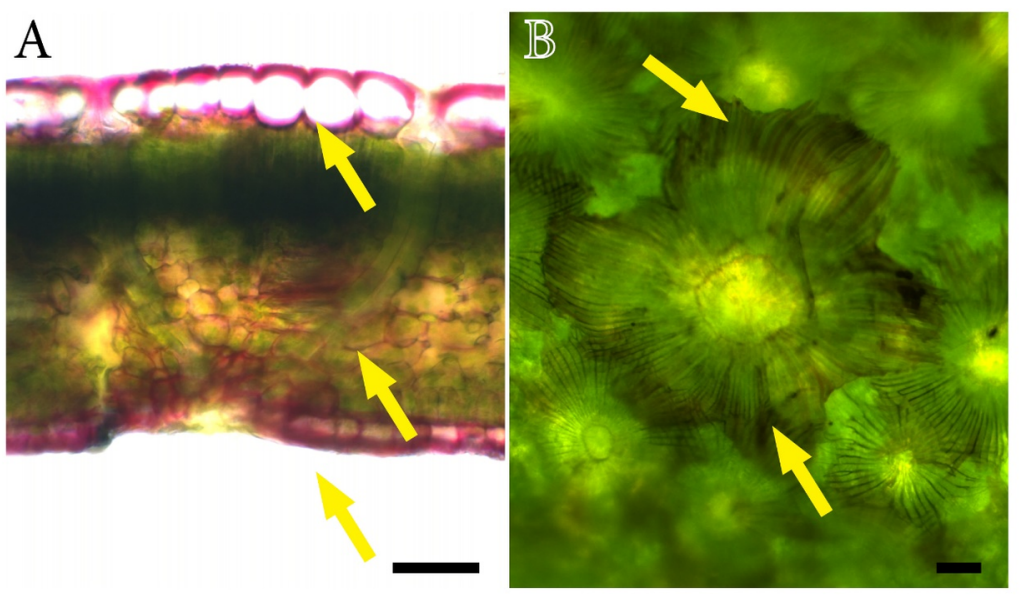




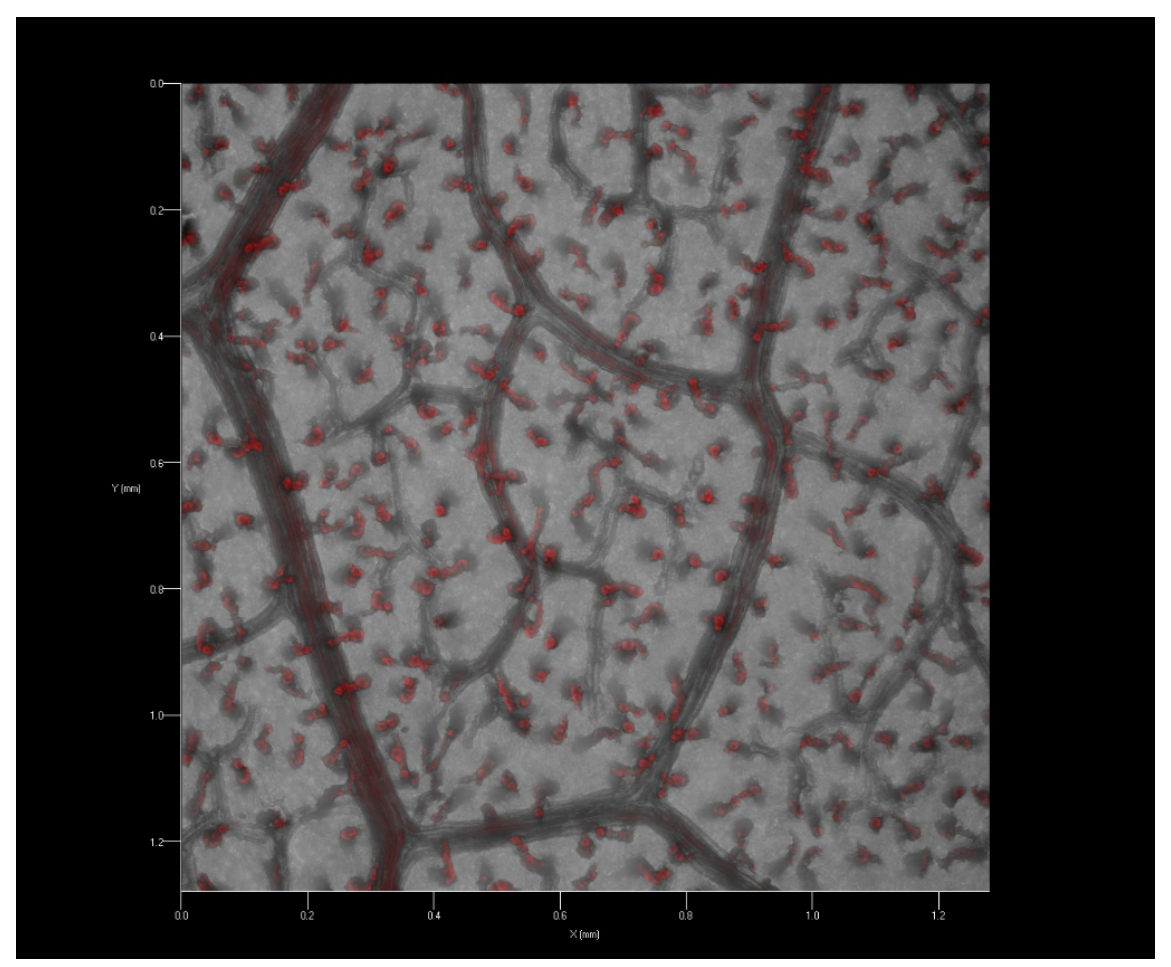

Figure S3: Localization of arabinogalactan proteins in the idioblasts (red color) with the beta-glucosyl Yariv reagent in whole mount tissues of the cleared leaves.

Video S1: Abaxial loading of $0.5 \mu \mathrm{L}$ water droplets in a living plant of Capparis odoratissima, recorded every 5 seconds. Time in min.

Video S2: Adaxial loading of 0.5 $\mathrm{L}$ water droplets in a living plant of Capparis odoratissima recorded every 5 seconds. Time in min.

Video S3: Abaxial loading of 0.5 $\mu \mathrm{L}$ water droplets of Lucifer Yellow on a living plant of Capparis odoratissima, recorded every 5 seconds. Time in min.

Video S4: Adaxial loading of $0.5 \mu \mathrm{L}$ water droplets of Lucifer Yellow on a living plant of Capparis odoratissima, recorded every 5 seconds. Time in min. 

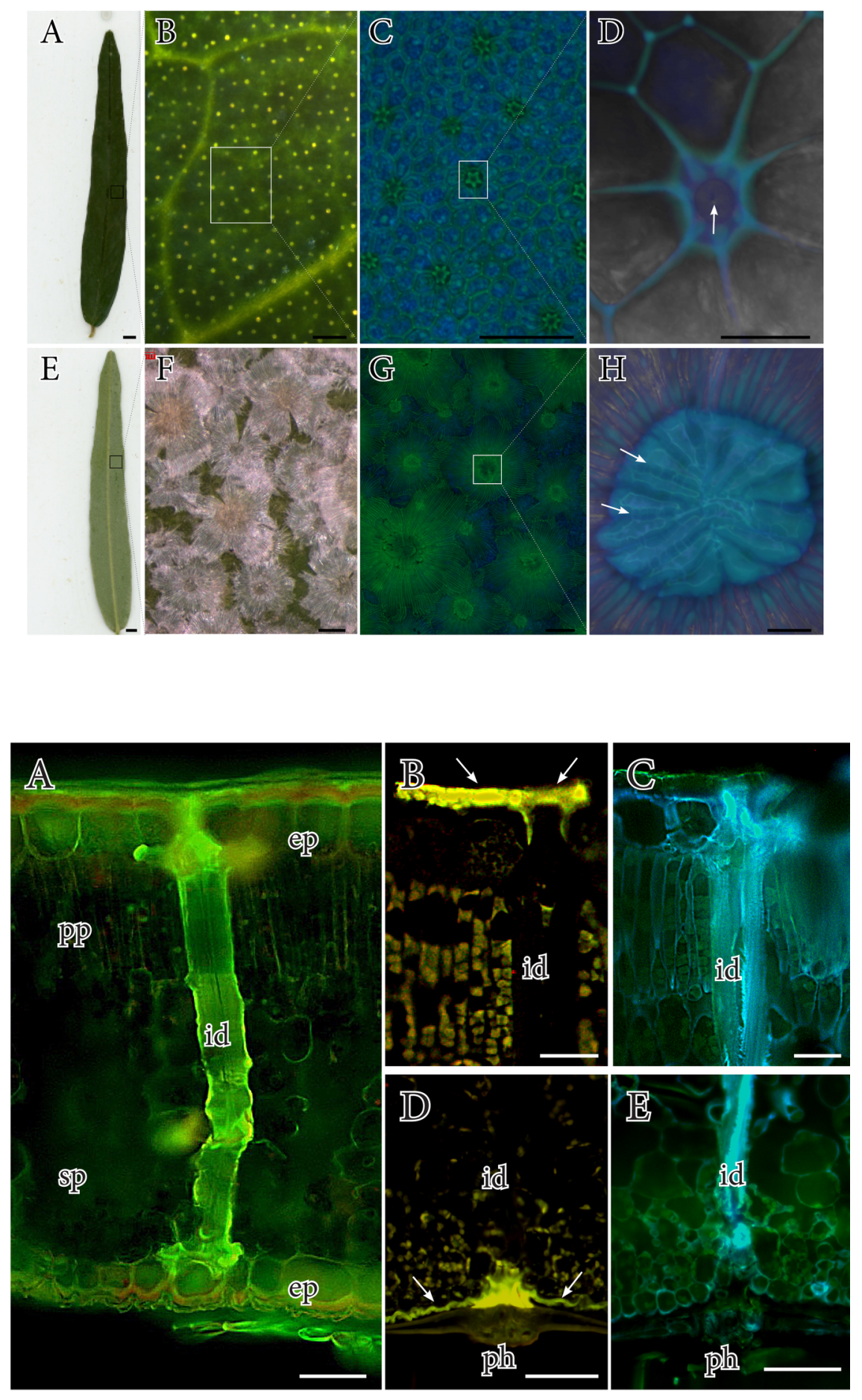

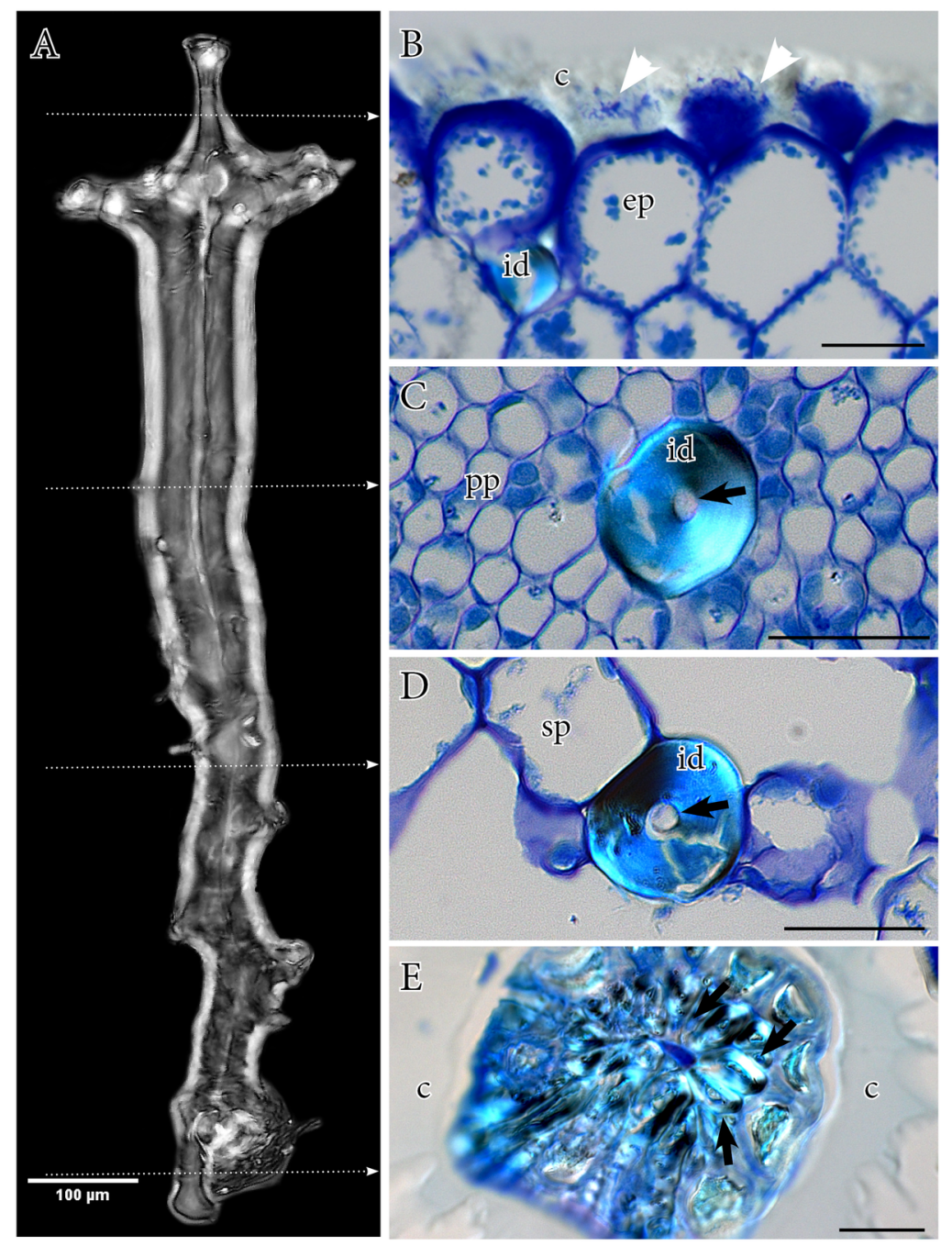


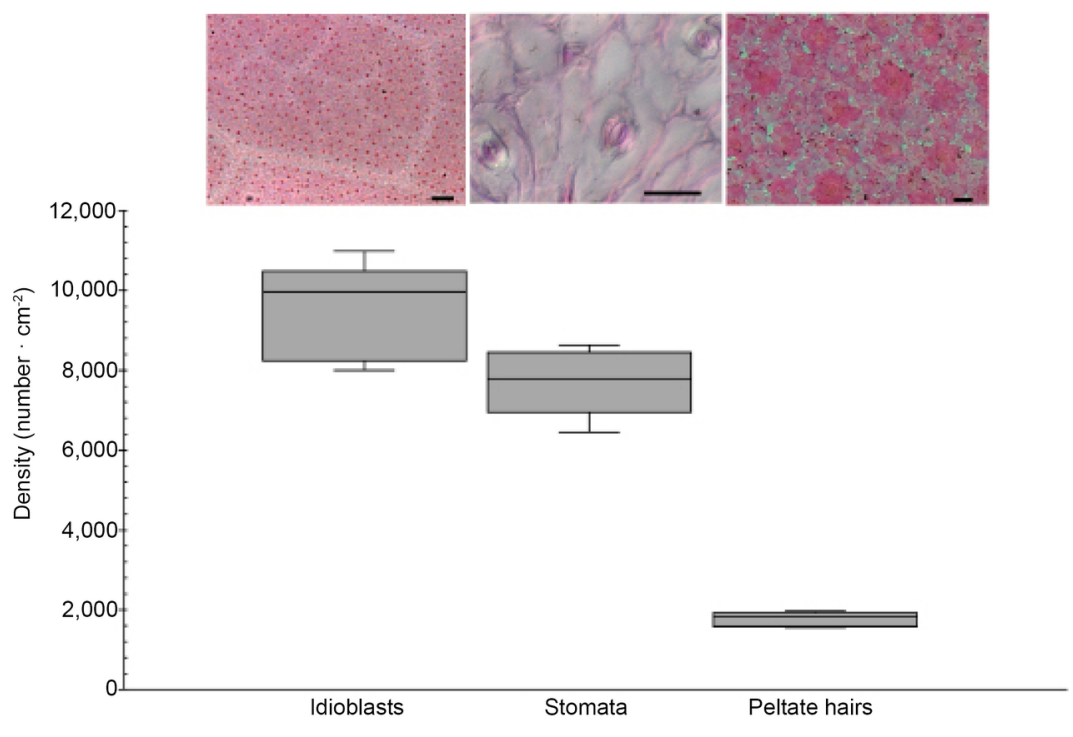

A
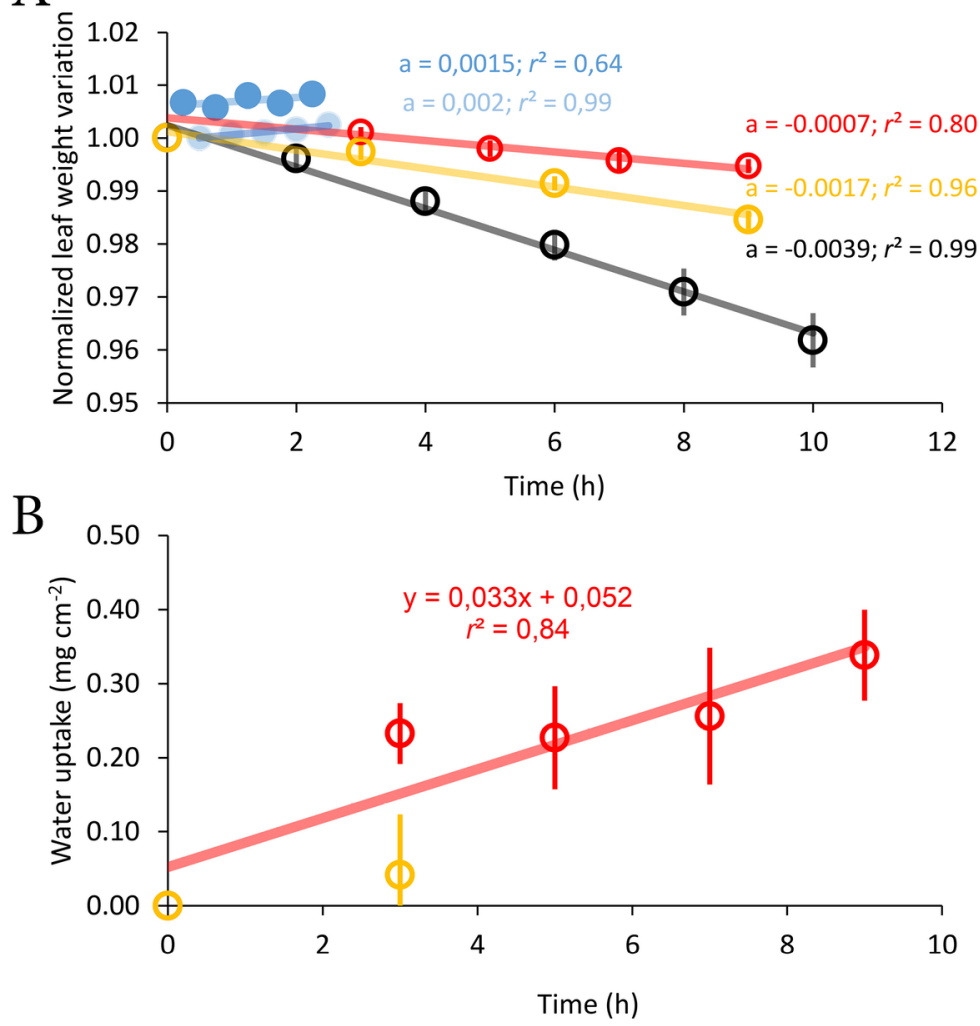


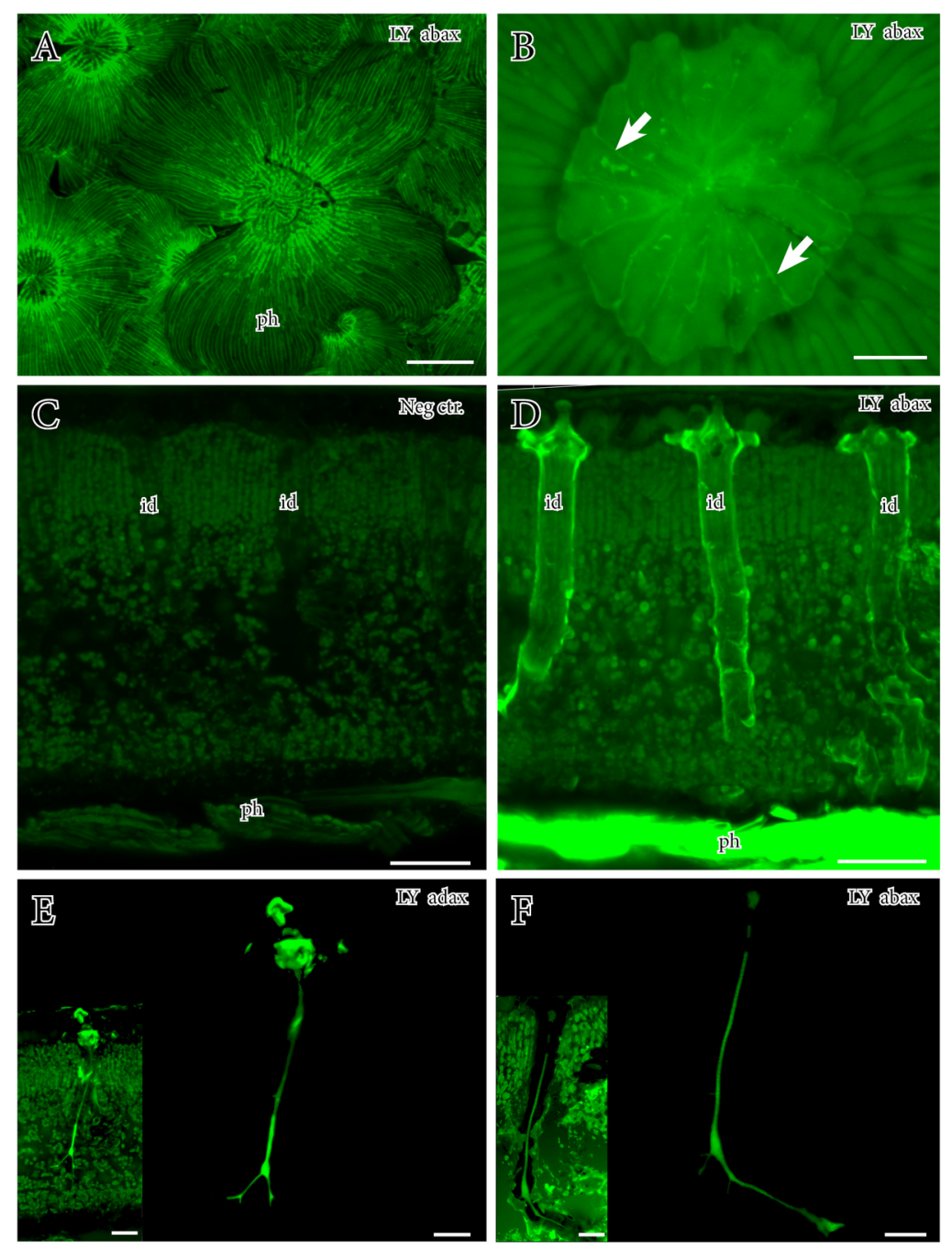



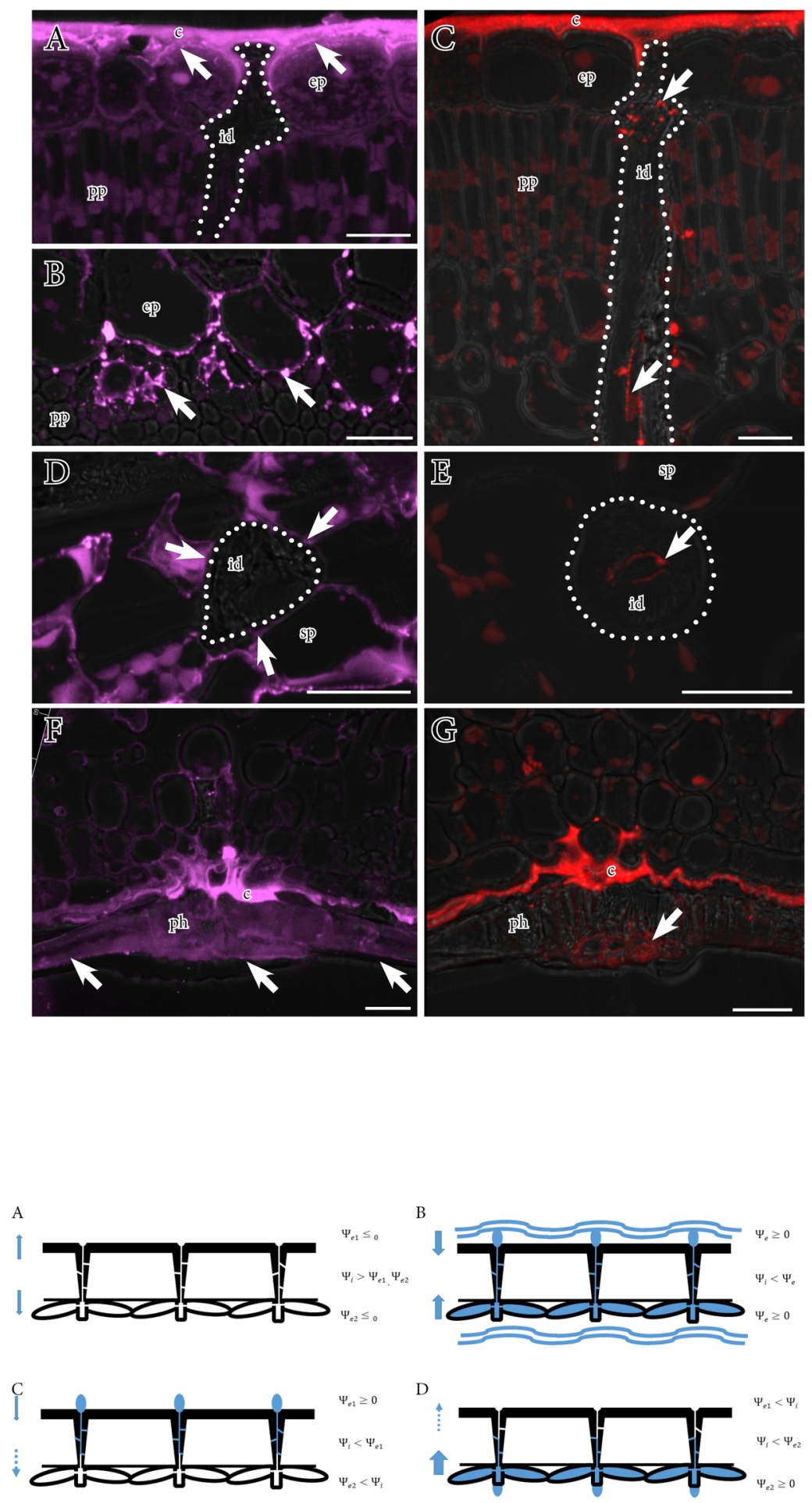